Article

\title{
The Design of New Technology Supporting Wellbeing, Independence and Social Participation, for Older Adults Domiciled in Residential Homes and/or Assisted Living Communities ${ }^{\dagger}$
}

\author{
Joan Cahill ${ }^{1, *(\mathbb{D})}$, Sean McLoughlin ${ }^{2}$ and Sean Wetherall ${ }^{2}$ \\ 1 School of Psychology, Trinity College Dublin, Dublin 2, Ireland \\ 2 Oneview Healthcare, Blackrock Business Park, Blackrock, Co., Dublin, Ireland; \\ smcloughlin@oneviewhealthcare.com (S.M.); swetherall@oneviewhealthcare.com (S.W.) \\ * Correspondence: cahilljo@tcd.ie; Tel.: +353-1-896-1623 \\ + This paper is an extended version of our paper in Proceedings of AAATE2017 Congres, Sheffield, UK, \\ 13-14 September 2017; with permission from IOS Press.
}

Received: 15 December 2017; Accepted: 24 January 2018; Published: 26 January 2018

\begin{abstract}
Purpose: The purpose of this study is to identify and validate the requirements for new technology supporting wellness, independence and social participation for older people domiciled in residential homes and/or assisted-living communities. Method: This research adopts a stakeholder evaluation approach to requirements elicitation and user interface design. Specifically, the study design combines several qualitative human-machine interaction (HMI) design frameworks/methods, including realist ethnography, scenario-based design, persona-based design, and participatory design. Findings: New technology should reflect positive values around ageing and link to psychosocial models of successful ageing, and biopsychosocial models of health and wellbeing. Resident autonomy, wellness and social participation cannot be conceptualized outside an understanding of the relationships older adults have with others. The design remit for this technology is to enable a resident experience that is similar to living at home. New technologies should facilitate wellness and communication/connection, and not simply risk assessment. New technology provides an opportunity to bridge existing information gaps between care planning, care assessments and daily care. Overall this technology needs to be intuitive and uphold the resident's dignity and rights. Person-to-person interaction is central to care delivery. The introduction of new technology should enhance this interaction, and not threaten it. Conclusions: Future assisted-living (AL) technology should be premised by biopsychosocial models of wellness and support relationships between older adults and members of the personal and professional community. New assisted-living technology affords the possibility for improved social relationships, enhanced wellbeing, better quality of care, and independence. Such technologies require careful consideration in relation to adapting to age/condition and managing issues pertaining to resident consent, privacy and human contact.
\end{abstract}

Keywords: ageing; assistive technology; relationship-centered care; care homes; wellbeing; social participation; stakeholder evaluation

\section{Introduction}

\subsection{Introduction to Study Problem}

The purpose of this study is to identify and validate the requirements for new technology supporting wellness, independence and social participation for older adults, domiciled in residential homes and/or assistive living communities. This is a multifaceted research question/problem. 
Addressing this problem requires integrating insights from several diverse strands of theoretical and applied research, and drawing practical implications from a design perspective. This is complicated by the fact that existing relevant research fails to deliver adequate instruction in relation to user, technology and design requirements. In many cases, salient questions pertaining to the application of underlying theory, end user need, expected benefits, user acceptability, and ethical issues are insufficiently explored. Further, the introduction of these technologies raises several interrelated human factors issues concerning social participation and human contact. Arguably, the available literature does not adequately interrogate these issues. Overall, further field research with older adults and relevant stakeholders is required.

\subsection{Review of Existing Research and Gaps}

Biopsychosocial models of health and wellbeing provide a useful starting point for thinking about technology requirements. Such models emphasize the varied determinants of wellbeing including, medical, psychological, family and social factors [1,2]. However, the available literature does not discuss the practical application of these models. How might new technology be designed to promote the biopsychosocial dimensions of wellbeing? Are some functions more or less relevant in terms of contributing to resident wellbeing?

Many different accounts of successful ageing have been proposed. Biomedical models focus on the avoidance of disease and disability [3]. According to Rowe and Kahn, successful aging is multidimensional encompassing the avoidance of disease and disability, the maintenance of high physical and cognitive function, and sustained engagement in social and productive activities [4]. Similarly, psychosocial models focus on life satisfaction, social participation, functioning, and psychological resources [5,6]. The implications of these models in terms of the advancement of assistive living (AL) technology are not discussed.

Models of care delivery abound. Patient-centered care focuses on visits involving care of generally chronic diseases [7]. In contrast, person-focused care "extends beyond communication because much of it relies on knowledge of the patient (and of the patient population) that accrues over time and is not specific to disease-oriented episodes" [8]. Advocates of relationship-centered care emphasize the importance of nurturing personhood and positive social relationships [9-11]. Again, the literature does not provide guidance in term of identifying how these models of care might be taken into account in relation to the specification of assistive living technology.

The concept of autonomy refers to exercising individual choice and being responsible for oneself [12]. As human relationships are based on mutual dependence and partnership [13], autonomy must be understood in the context of these relationships [14]. To this end, the concept of relational autonomy has been posited [15]. Several studies substantiate the link between self-determination/autonomy and quality of life for older adults in residential context [16,17]. By implication, future technologies might support relational autonomy for older adults.

New technologies are being advanced to support the needs of older people living independently and in residential homes and/or assisted-living communities. Generally, this involves the use of a range of connected devices (i.e., TV, tablets, smart phones, wearables and environmental sensors). Critically, these technologies are not defined in relation to relevant theory/concepts. This includes relational autonomy, relationship-centered care, successful ageing and wellness. Moreover, many of the technologies deployed in residential care contexts are associated with keeping the resident safe. Arguably, there is less of an emphasis on independence and supporting social participation. Further, fundamental ethical problems have been raised in regard to existing monitoring technologies [18]. The use of close circuit television (CCTV) and its impact on human rights and civil liberties is well documented [19]. In addition, certain practical issues associated with these new technologies have been highlighted. Wearables are becoming more popular in relation to activity and health monitoring (for example, pendants and wrist watches). Older adults have increased skin sensitivity which makes wearing certain wearable sensors an uncomfortable experience. Although wearables may be available, 
there is no guarantee that they will be used (i.e., the resident may remove them or not wear them at all) [20]. In relation to fall alerts (where pendants are typically used), a high number of falls occur at night when the resident is less likely to be wearing it [20].

The introduction of these technologies raises several inter-related human factors issues pertaining to social participation and human contact, which thus far have not been adequately explored. This includes issues pertaining to addressing (a) loneliness/social participation, (b) the potential reduction in human contact arising from the introduction of such technologies (i.e., care automation), and (c) the potential for human error/neglect arising from either a reduction in human contact (i.e., care automation), and/or poor communication between staff and residents with communication difficulties. Such issues warrant careful consideration. Social isolation and loneliness is a common experience for people of all ages including older people [21]. Typically, older adults domiciled in residential homes/assisted-living communities are at a risk of social isolation and loneliness. Residents may have lost their partner, they may have limited social ties, and the residential home may be located at a geographical distance from family / friends.

Social isolation can have a negative impact on an older person's mental and physical health [22]. Khosravi, Rezvani and Wiewiora (2016) have identified eight different technologies that have been applied to alleviate loneliness and social isolation for older adults [23]. This includes general information communication technology (for example, Internet and Email), video games, robotics, personal reminder information and social management system, asynchronous peer support chat room, social network sites, Telecare and 3D virtual environments [23]. Although such technologies can be used to reduce social isolation among older people, more studies are needed to evaluate the effectiveness of these technologies [23]. In 2014, the Campaign to End Loneliness identified several challenges concerning the use of technology to overcome loneliness [24]. Sending a message/making a Skype call necessitates some prior form of social relationship with other persons (i.e., message recipients). Finding people to communicate with is a significant issue for those with limited social connections [24]. Other issues raised include: a lack of training in relation to using the technology, offering training or technology can be perceived as pushing change onto people and a lack of accessibility for people with sight loss or early onset dementia [24].

The rate of clinical incidences/errors resulting in patient harm and/or mortality is higher for older people and persons with poor communication ability (i.e., persons with disability and/or cognitive impairment) [25]. In care settings, family members/friends play an important role in relation to monitoring the quality of care and advocating on behalf of the resident/patient (relational autonomy). Often family members fill care gaps/breaches. These protections are not in place for persons with limited social ties/family participation. Given this, such persons are potentially more at risk in relation to poor quality care and neglect. The introduction of future technology may potentially amplify this problem. Such technology may reduce face-to-face interaction between residents and caregivers. The existing literature does not provide guidance in terms of how this is to be addressed.

Residential care facilities have historically addressed societal goals as opposed to addressing the needs of those living in them [26]. Nursing goals can often be different to resident goals. To this end, Charters of rights for older people living in care homes have been advanced both generally [27] and in the context of residents with dementia [28]. These follow from the European Convention on Human Rights [29]. In relation to the European Charter on Human Rights, several articles are salient to assisted living - including Article 5 (the right to freedom and security), Article 8 (right to family and private life) and Article 27 (prohibition of abuse of rights) [29]. In parallel, new legislation is being introduced to ensure that issues concerning capacity and consent are properly addressed for adults with disabilities, early cognitive decline and/or dementia (for example, Assisted Decision-Making (Capacity) Act 205) [30]. Evidently the proposed new technology needs to be articulated from a rights perspective and consider issues pertaining to user acceptability, choice, and privacy. 


\section{Materials and Methods}

\subsection{Research Objective, Questions \& Scope}

The objective of this study is to identify and validate the requirements for new assisted-living (AL) technology facilitating wellness, independence and social participation, for older people domiciled in residential homes and/or assisted-living communities [31,32]. In this regard, three research questions are defined:

- Q1: What are the requirements for new technology facilitating wellness, independence, and social participation, for older adults domiciled in residential homes and/or assisted-living communities?

- Q2: What ethical issues, user acceptability issues and broader stakeholder concerns need to be addressed, and how?

- Q3: How can relevant theoretical models (including concepts of relational autonomy, relationshipcentered care approaches, biopsychosocial models of wellness and models of successful ageing), be utilized from a technology design perspective?

In terms of scope, the primary focus is on the resident experience and the associated resident solution. Solutions for other stakeholders (i.e., nurse, care assistant and family) are being advanced for the purpose of (1) complementing workflows associated with the resident solution (for example, a nurse accessing a resident wellness survey), and (2) providing task support for these other stakeholders in relation to addressing resident wellbeing (for example, a nurse viewing resident profile information and/or reporting on resident wellbeing). Appendix A provides more information on the specific solutions advanced.

\subsection{Background}

Human factors research is being undertaken as part of an industry and academia collaboration involving researchers from Trinity College Dublin (TCD) and Oneview Healthcare [31,32]. As defined in ISO 6385, human factors concerns "the practice of designing products, systems, or processes to take proper account of the interaction between them and the people who use them" [33]. Prior to the commencement of this research, a preliminary "assisted living" (AL) product was advanced by the Oneview "assisted-living product team". The initial concept, functionality and user interface (UI) design was specified based on market analysis data and feedback from subject matter experts and prospective clients. Currently, this preliminary product is being elaborated.

Human factors research is being undertaken in parallel to this product development/elaboration. In this context, there is a requirement to (1) provide ongoing feedback to the product team, (2) define preliminary requirements at an early stage, (3) quickly translate field research findings into design requirements (i.e., prototyping), (4) iteratively elaborate on requirements and design solutions and (5), validate the design solution, taking into account those functions that deliver benefits to different stakeholders (i.e., co-design/evaluation). Overall, the proposed methodology takes into account the above requirements. The collaboration model is defined in relation to the provision of research services elapsing over a two-year period. The product owner and members of the project team are members of the AL "community of practice" and are involved in certain research activities. Specific research outputs are integrated into product development, following a review by the product owner and project team. As detailed in Appendix B, this has involved the iterative handover of personae, requirements specifications and prototypes, at predefined project milestones.

\subsection{Overview of Study Design}

This research applies the gold standard for human factors action research pertaining to new technology development. Specifically it deploys a stakeholder evaluation approach to requirements elicitation and user interface design [34]. This is underpinned by the participation of a "community of practice" [35]. The study design combines several qualitative human-machine interaction (HMI) design 
frameworks/methods. In relation to needs analysis, the methodological approach is underpinned by realist ethnography [36-38]. The emphasis is on understanding lived experience and the context and meaning of experience [39] —and especially, the interactions between older people and relevant stakeholders in their personal and professional community (i.e., nurses, family members, carers, friends, GP and specialists). In relation to requirements specification, prototyping and design/evaluation activities, the methodology combines aspects of "personae-based design" [40], "scenario-based design" [41] and "participatory design" [42].

In line with Wenger's approach (1999), the stakeholder evaluation approach involves the active and ongoing participation of stakeholders throughout the project [35]. As part of this, a "community of practice" comprising internal and external stakeholders has been advanced [35]. As indicated in Table 1 below, both internal and external stakeholders participate in different research activities. The composition of the community of practice is outlined in Appendix C.

Table 1 below provides a summary of research phases and activities and what has been achieved. To date, forty-seven interviews have been undertaken (external stakeholders: $N=38$, internal stakeholders: $N=9$ ). This includes interviews with older people living independently, aged care nurses, family members, volunteers and experts in ageing and dementia. Preliminary observations have been undertaken in two day hospitals providing care for older people in the community. Initial observations have also been undertaken at a residential home. Following the analysis of field research findings, a Version 1 prototype was developed for use in the co-design activities. The first phase of co-design/evaluation sessions with the stakeholder panel $(N=6)$ has been completed. Currently, the second phase of co-design activities is underway $(N=3)$.

Table 1. Research Phases and Activities.

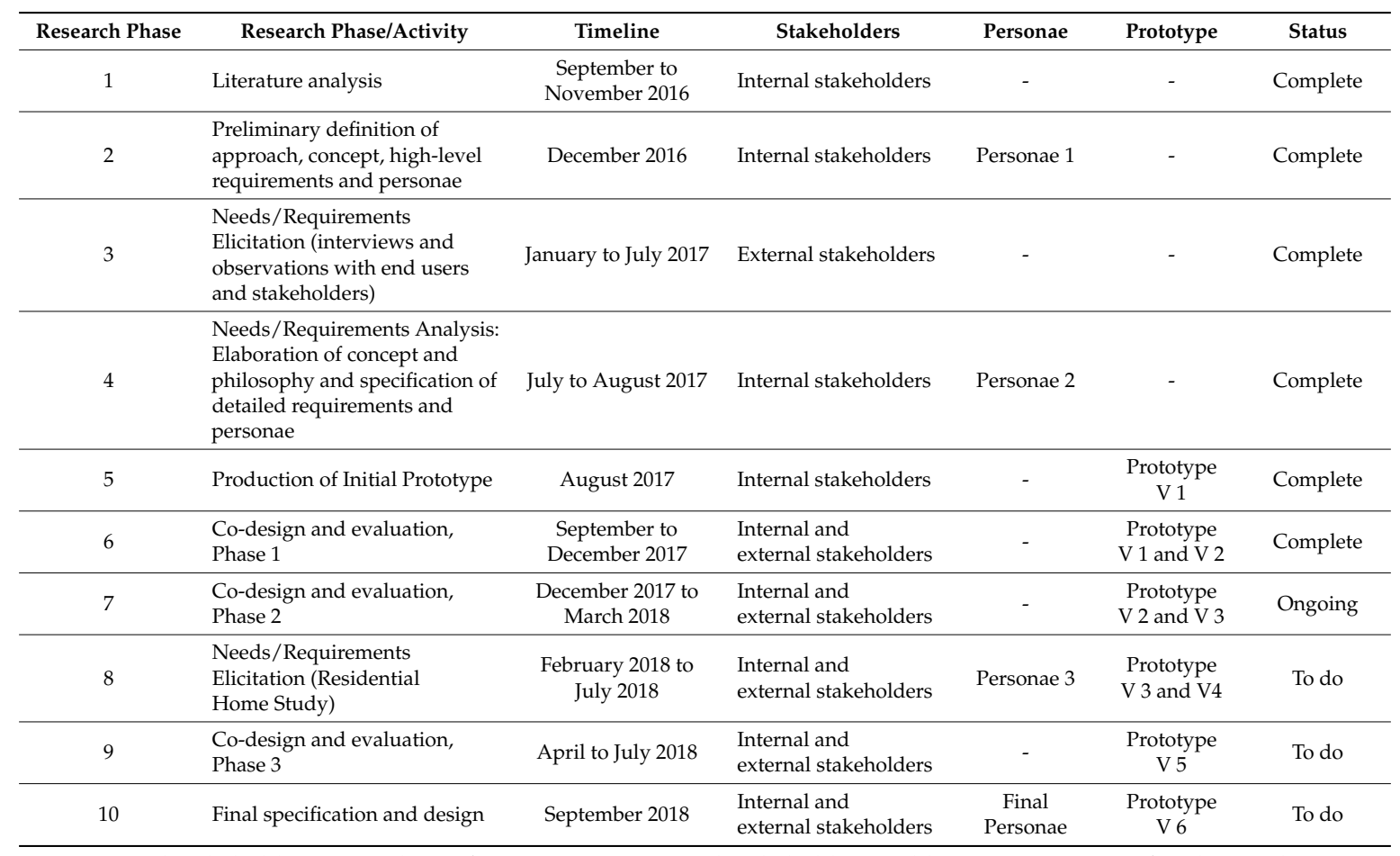

Internal stakeholders = members of project team; External stakeholders = older persons, nurses, family members, dementia experts, residential home managers/owners and gerontologists.

To date, the stakeholder panel comprises 47 participants. Internal stakeholders $(N=9)$ include members of the assisted-living project/research team (i.e., human factors researchers, user experience designers, developers, product owners, nurses and experts in health informatics). External stakeholder comprises two participant groups (1) end users and (2) other stakeholders ( $N=38$ participants). 
End users include older adults living independently with/without care in the home, potentially living with one or more morbidities, with different levels of functional and cognitive ability and an age range of between 60 to 90 years. Other stakeholders include three sub-groups, (a) family members, (b) formal aged care staff-(i.e., aged care nurses, care assistants and community nurses) and (c) other stakeholders (i.e., GPs, geriatricians, experts in ageing, volunteers in active ageing groups and volunteers/staff of relevant groups/societies). It is anticipated that the composition of the external stakeholder panel will broaden following Phase 8 Research (i.e., participation of older adults, geriatric nurses and administration personnel).

Older people, especially those living with cognitive impairment are a vulnerable group and safeguarding their dignity, rights and privacy is a key concern. The study has been conducted in accordance with the principles of the Declaration of Helsinki (as amended in 2013) [43]. It is intended that older people with benefit from this research (Principle 20). Participant decision making in terms of participating in research was based on a full understanding of what is involved (Principle 20). This was a process, rather than simply a document to be signed. All participants gave their voluntary informed consent for inclusion before they participated in the study (Principle 25). Every precaution has been taken to protect the privacy of participants and the confidentiality of their personal information (Principle 24). Research methods have received ethics approval from the School of Psychology, Trinity College Dublin, Ireland. Phase 8 Research (needs analysis at post-acute care facility) has also received ethics approval from the Institutional Review Board of the Mater Hospital, Dublin.

\subsection{Literature Review and Development of Approach, Initial High Level Requirement, Sceanrios and Personae}

The literature view focused on providing a qualitative summary of existing evidence pertaining to successful ageing, wellbeing, care approaches, stakeholder need, technology requirements and ethical issues. Relevant theoretical literature pertaining to successful ageing, wellbeing and care approaches was reviewed. Policy documentation and research studies pertaining to the advancement of assisted-living technologies were also examined. Further, an analysis of the existing competitor offering was undertaken. Lastly, the researcher reviewed requirements documentation provided by three prospective customers.

The output of this was a definition of the overall concept and approach, a specification of preliminary personae for older adults in different contexts (for example, residential care, assisted-living communities, home care and palliative care), the specification of initial scenarios, and the definition of preliminary requirements.

Preliminary personae and scenarios were derived from analysis of literature review findings. Following the approach of Rosson and Carroll (2002) and Goodwin (2011), the initial high-level scenarios describe the future task practices/workflows supported by this new technology [44,45]. Both the preliminary personae and scenarios were further refined following field research with stakeholders. As outlined in Appendix D, all proposed resident functions/requirements were defined in relation to (1) end user states/benefits, (2) biopsychosocial model of wellness and (3) successful ageing models.

\subsection{Needs/Requirements Elicitation (Interviews and Observations)}

Semi structured interviews were conducted in person either at the participants home or their workplace. Four separate interview guides were developed to support interviews with (1) older adults, (2) family members, (3) nurses/care staff and, (4) ageing experts and volunteers. Specific interview questions linked to key research questions and relevant themes emanating from the literature review. In each case, the participant was posed questions pertaining to their own experience and needs, and also that of other stakeholders. Overall, forty-seven interviews were conducted with external $(N=38)$ and internal $(N=9)$ stakeholders. In terms of interview duration, 25 long interviews (approx. average duration $2 \mathrm{~h}$ ) and 22 short interviews (approx. average duration $0.5 \mathrm{~h}$ ) were undertaken. In all cases, the researcher took written notes. There was no audio or video recording. 
In terms of participant breakdown, external stakeholders included 11 older adults (mean age mean age 79.36 years), 7 family members, 5 experts in ageing/dementia, 1 ICT expert, 4 nurses, 5 representatives spanning two "care for the elderly" day services, 3 representatives from a post-acute care service, and 2 representatives from a residential home. Appendix E provides an overview of the profiles of older adults. Internal stakeholders comprised 1 product owner, 2 experts in ICT for ageing, 2 former nurses currently working in healthcare ICT-based roles, 2 Graphic Designers/User Experience Designers and 1 GP/Health Informatics Expert.

Preliminary observations were undertaken taken at two day hospitals and one residential home. A short walk around was undertaken at one day hospital (approximate time: $0.5 \mathrm{~h}$ ). The researcher was accompanied by the Assistant Director of Nursing. A detailed walk-around was undertaken at a second day hospital (1 day). Here the Researcher was accompanied by the Nursing Manager, along with other staff (Dietician, Case Manager and Pharmacist). The researcher observed several settings-case rooms, occupational therapy room, service user interviews and assessments and service user social activities/interaction in the common room. Further, the researcher received a walk-through of relevant technologies used by different staff, to document casework. A third observation was undertaken at a residential home (approx. time $2 \mathrm{~h}$ ). Here, the researcher visited indoor and outdoor social spaces, dining rooms, activity rooms and resident rooms accompanied by the residential home owner. In all cases, the researcher collected artifacts from the settings including paper forms and information leaflets. In relation to the second day hospital, the researcher took screenshots of the technologies used by the different roles, and schedule/workload information presented on nurse whiteboards.

\subsection{Needs/Requirements Analysis and Refinement of Scenarios and Personae}

Following the interviews/observations, the researcher's notes were transcribed. Data analysis focused on understanding/defining the lived experience of older adults, care approaches and specific stakeholder technology requirements. A thematic analysis of field research findings was undertaken [46]. The thematic analysis was initially driven by the research question and associated theory (i.e., not inductive). In support of this, a preliminary coding/data frame with high-level nodes was defined. An initial review of sample manuscripts across different stakeholders was undertaken. Following this, the coding frame was refined and sub-nodes were identified (i.e., link to emergent themes). Appendix F provides an example of the final coding frame. The qualitative data analysis software NVivo was used to support the thematic analysis of data.

\subsection{Production of Intitial Prototype}

Stakeholder personae and scenarios were used to (1) support problem solving around stakeholder requirements and (2) the user interface design of prototypes. Early stage prototypes were developed using the wire-framing tool Balsamiq. The primary focus was on the resident solution. Three different prototypes linking to three high-level resident contexts were defined-(a) resident is considering moving to residential home, (b) resident is in the admissions process and (c) resident is domiciled in residential home. The specification of (c) involved the parallel definition of complementary prototypes for other stakeholders. This includes prototypes for nurses, care assistants and family members. The initial prototype was reviewed by members of the project team (internal stakeholders, $N=2$ ), in advance of the co-design activities.

\subsection{Codesign and Evaluation: Phase 1}

As indicated in Table 1, the first phase of co-design/evaluation occurred after the analysis of field research and the specification of the initial prototypes (prototypes 1). The evaluation focused on eliciting stakeholder feedback regarding the high-level product concept for the resident application, and a subset of the other stakeholder solutions (for example, nursing staff, families, pre-admissions and admissions). External stakeholders included older adults $(N=4)$ and nurses $(N=2)$. In advance of viewing the prototypes, participants reviewed a short Microsoft power-point 
presentation that provided a background to the research and preliminary findings, a summary of the different applications and functions, and an example persona. The example persona referred to Frank. Frank is 71 years old, has Type A Diabetes, moderate functional decline and early cognitive decline. The review/co-design of prototypes then commenced. The initial prototypes were demonstrated to stakeholders using a laptop computer. Participants were invited to review prototypes based on (1) their own experience and need, and (2) on the imagined situation of Frank. Feedback pertaining to user need, user expectations, user acceptability and issues related to ethics and privacy was elicited. Appendix $G$ features some examples of this version 1 prototype.

\subsection{Codesign and Evaluation: Phase 2}

As indicated in Table 1, the second phase of co-design is currently underway. Overall, this has involved the same procedure as phase 1 . However, the second phase of co-design is focused on the resident and nurse applications only. The prototypes demonstrate basic level functionality on the tablet (i.e., touch interaction). The focus here is on (1) eliciting more specific usability feedback (i.e., task workflows, interaction style, nomenclature and iconography) and (2) following up on certain key human factors issues (for example, reduction in human contact). To date, the participant panel includes older adults $(N=2)$ and a nurse $(N=1)$.

\subsection{Next Steps}

Two further phases of co-design/evaluation with the participant panel are planned. These will focus primarily on the (1) resident solution and (2) nurse/care givers solutions. In relation to (1), this will involve the evaluation of a working product in a test environment (i.e., resident room with full sensor kit). Further, it may include a demonstration of a "multi-modal" resident solution (including voice, touch and potentially gesture interaction). In relation to (2), the primary focus will be (a) evaluating those functions which pertain to resident wellness (for example, reporting on resident status and activity, ensuring meaningful interactions with the resident, evaluating resident changes and making a case for new assessments/care plan updates), and (b) exploring how best to manage issues around reduction in human contact/optimizing human contact in care delivery.

In addition, field research will be undertaken at a post-acute care community unit and at a residential home (Phase 8). As part of the initial needs/requirements elicitation (phase 3 research), the researcher previously undertook preliminary observations and interviewed staff members at these sites. This phase of field research will involve the participation of patients, nursing home residents and nursing/care staff. This will involve a mix of realist ethnography and co-design/evaluation. Collectively, the output of these activities will feed into the final prototype specification.

\section{Results}

\subsection{Overview}

This section presents the results of Phase 3 research (i.e., needs/requirements elicitation). First, general findings reflecting the needs/perspectives of all stakeholders are reported. Following this, specific stakeholder technology requirements are reported. This spans older people, nurses, care assistants, family members and care home mangers/owners.

\subsection{General Findings}

There was general agreement that independence for seniors is linked to interdependence. That is, independence for older adults necessitates support from other actors in an older person's personal and professional community.

Participants emphasized the importance of the psycho-social dimensions of ageing. Overall, there was agreement that the technology should support wellness, independence, social connection/ 
participation and privacy. Table 2 below provides a summary of the specific states to be (1) promoted, (2) managed and/or mitigated and, (3) avoided.

Table 2. Lived Experience, States and Benefits.

\begin{tabular}{|c|c|c|}
\hline Promote/Support & Manage, Mitigate and Reduce & Avoid \\
\hline Wellness & Loss of privacy & Infantilization \\
\hline Social Participation & Physical discomfort & Objectification of the dementia patient \\
\hline Privacy and protection of personal sphere & Communication difficulties & Unsafe behavior \\
\hline Communication & Fear & Reduction in human contact \\
\hline Identity & Difficulty with new information & \\
\hline Empowering Person & Difficulty with change & \\
\hline Dignity/respect & Restlessness & \\
\hline Purposeful living & Feeling lost & \\
\hline Active and healthy living & Overstimulated & \\
\hline Sense of community & Stress & \\
\hline Acceptance & Confusion & \\
\hline Resilience/coping & Agitation & \\
\hline Self-management of health & Negative thinking & \\
\hline Calmness & Depression & \\
\hline Engagement & Aggression/Anger & \\
\hline Sense of confidence in own ability & Sleep disturbances and sun downing & \\
\hline Awareness (including sensory awareness) & Suspicions and delusions & \\
\hline Nurturing person & Self-neglect & \\
\hline Citizen participation & & \\
\hline
\end{tabular}

Concepts of "relationship-centered care" resonated for all participants. It was agreed that the proposed stakeholders for this new technology might include residents, family members, nurses, care assistants and administrative staff (i.e., staff working in admissions and involved with co-ordination with family members). As observed by participants, all such stakeholders might benefit from this technology; specifically, in relation to promoting meaningful interaction, monitoring the resident (i.e., tracking health status, activity, mood and pain), and addressing individual needs on a real-time basis.

Older adults, family members, community nurses and ageing experts expressed a strong preference in relation to supporting older people remaining in their own homes. Daily routines were reported as closely bound up with "being in their own home" and "having access to their own things/furniture". Also, the home was reported as "a place closely associated with memories and personal identity". In this regard, it was agreed that future technology should enable older adults to remain in the home. Older adults might first interact with AL technology in their private homes. Aspects of this technology might be replicated in a residential context. Older adults and family members expressed concerns/fears in relation to the transition to a residential home. Consistently, this was reported as something to be "put off" until "it becomes inevitable".

Participants reported that many older people domiciled in residential homes have early cognitive decline and/or dementia. As such, their ability to interact with tablet systems might be limited. However, participants noted that the advancement of solutions for nursing and care staff along with family members would be beneficial for residents with dementia.

All participants highlighted the need to distinguish between a residential care context and an acute care context. As reported by participants, although residents may need help with specific activities of daily living (ADL) and/or have cognitive impairment, "they are still living" and "require purposeful activity". Further, "the residential home is their home". Unlike a hospital setting, "the intention is that residents live in the residential home as they would do in their own home". In this regard, it was suggested that the proposed design remit for this technology might be to enable a resident experience similar to 
"living in one's own home". Participants characterized "home" in relation to (1) free movement, (2) eating and sleeping in different spaces, (3) spending different parts of the day in preferred living/social areas (including outdoor spaces), (4) having control over their direct environment/room (i.e., light, noise, heat, opening/closing of windows and doors), (5) having access to social/communal spaces, and (6) the ability to receive visitors. Moreover, participants observed that just like a private home, (7) the residential home must be integrated with the community. Where possible, the resident should be able to come and go-engaging with the outside world on their own terms. Many participants (and specifically ageing experts) remarked on societal tendencies to segregate older people (i.e., confined to residential homes which are removed from the community).

There was a general concern that the introduction of this technology might be focused on serving organizational goals (i.e., reducing the costs of care and risk assessment), as opposed to having a resident focus. All participants suggested that the technology might reflect a balance between resident needs and organizational needs (including needs of nurses and caregiving staff). In addition, family need might also be considered.

Every older person is unique and has specific needs and different abilities. Accordingly, it was agreed that needs assessment and customization is a necessary first step in relation to the implementation of such technologies for individual residents. All participants observed that AL technologies might be useful in relation to keeping residents active and socially engaged. It was noted that future technology might enable residents to maintain social connections and "keep in touch with family and friends". This was distinguished from "providing companionship". As reported by participants, a tablet solution can afford the opportunity to make a telephone or video/Skype Call. However, it cannot replace the lived experience of "being in a relationship" and/or "the company of family and friends" and associated communications/supports.

The application of passive technology to monitor resident safety, prevent falls and raise alarms (if needed) was welcomed by all (i.e., passive sensors in beds and activity monitoring sensors). Further participants noted that they wander management technology (i.e., door sensors and sensors in the environment), would be acceptable, if this meant that they could move around freely. Participants liked the idea that from a resident perspective, much of the technology might be happening in the background (i.e., bed sensors, sensors on windows/doors etc.).

All participants emphasized the importance of upholding resident rights and dignity. In particular, participants stated that personal and medical information should be protected (and not shared with other without permission) and that the technology should allow residents to have a voice (i.e., articulate their needs and concerns).

All participants highlighted the importance of in person care (i.e., person-to-person communication). Participants observed that we should not lose touch with the human element of care characterized by human presence and responsive/empathetic communication. Specifically, nursing participants observed that interaction with residents informs care plans, care assessments and family communications.

One of the big issues reported by all participants, is that the introduction of this technology (for example, activity sensors, bed sensors, fall sensors, health monitory technology [including wearables], smart room technology [control windows, doors and environment], and technology linked to virtual social participation) may lead to (a) a reduction in human contact, and (b) poor quality contact/care. Participants observed that if care staff are using the tablet while in the resident's room (i.e., reading information and completing forms), then this will negatively impact on certain key dimensions of person-centered care (for example, eye contact, touch, active listening and conversation). Moreover, participants noted that if monitoring is automated, and in person contact mostly initiated by electronic help requests, then this might become quite isolating for residents. For example, it might result in situations where residents only receive in-person contact if they request contact/help. As stated by one participant, "If the nurse can see on computer screen that I am ok, would they still call to my room?" It was 
suggested that new process/procedures should be designed to mitigate the potential loss of social contact arising from the introduction of this technology.

All participants highlighted the importance of the care assistant's role. Care assistants have significant interaction with residents-providing support for ADL (for example, dressing, washing, toileting, eating and drink, grooming, transport around the residential home), room cleaning and answering resident requests/calls. Further, care assistants often act as a communication/coordinating interface between the resident and nursing/administration staff.

Family members and nursing/care staff highlighted the importance of the resident's admissions process in terms of (1) eliciting information about the resident (i.e., who they are, what matters and key contacts) and (2) enabling a smooth transition to their new environment.

\subsection{Need and Requirements: Residents (Residential Homes and Assisted Living Communities)}

Overall, the Tablet might provide simple/fast access to a small number of functions that are meaningful to older people (as opposed to unnecessary noise). In this regard, participants stated that a level of realism in relation to proposed functionality is required. Functionality enabling access to entertainment functions (radio, TV), enabling the provision of feedback about mood/pain, supporting communication with family and friends, and the provision of access to photos/videos of family is useful. In addition, technology to support stress management and relaxation (automation of music at specific times, providing easy access to preferred TV stations/programs) is beneficial. Functionality to support self-management of health (education, access to medical records) might not be used. Participants noted that they would not like instructions/prescriptions from a piece of technology in relation to lifestyle choices, diet/exercise and social engagement. Having said that, it might be useful to view information about events, obtain medicine reminders and exercise prods, and/or participate in interactive physio exercises. Overall, this might "help keep a person engaged" and "give some purpose to the day'. In this regard, all participants welcomed the idea that during the admissions process, the tablet menu options and technology functions might be customized based on resident preferences and what is meaningful and realistic for them. Moreover, participants indicated that the resident might obtain training in relation to the use of the tablet. There was a mixed response to concepts around the provision of daily notifications for residents (i.e., engagement versus overload). It was suggested that such functionality might only be used by residents with significant computer experience and/or strong motor and cognitive ability.

\subsection{Need and Requirements: Nursing Staff}

From a nursing perspective, future systems might address issues around assessing patient acuity and enabling easy and real-time access to resident information (i.e., risk, health status, care plan, and assessments information). It was noted that medication reconciliation/management is a key task. To this end, new systems might support medication management across the process timeline (i.e., admissions, daily care, assessments, care planning and discharge (if respite\}). Electronic rounding systems might present resident well-being information elicited from resident self-reports, ambient sensors, and nurse/caregiver reports. Moreover, such systems might provide information about the person (i.e., social and personal history), what matters to them, important calendar dates (i.e., birthdays, wedding anniversaries), care routines and preferences. Participants reported that not all residents require the same level of rounding/checks. Also, in many cases, nurse observations may occur outside the resident's own room (i.e., corridors and communal/social space). Participants responded positively to the concept of developing a resident "wellness profile". It was suggested that all aspects of wellness be considered. For example, mood, pain, duration of sleep, bed exits, care/help requests, challenging behavior events, fall events, wandering events, eating/drinking, social activity and physical activity.

As reported by participants, one of the benefits of such a system is that might be used to build a picture of what is normal for a person (i.e., baseline context), so that any changes from this baseline might be easily flagged and interpreted by caregivers. For example, over time, the system (i.e., 
triangulation from sensors, nurse reports, resident surveys) might build a picture of a person's typical sleep patterns (i.e., two bed exits during the night, and $6 \mathrm{~h}$ sleep). Deviations from this "baseline normal" might be highlighted with yellow/amber/red icons to indicate a change from normal. As reported by participants, this would be particularly useful for short-term contract/agency staff (i.e., such staff may not have had sufficient time to develop a rich picture of the resident). Further, this would help in relation to error avoidance/mitigation (i.e., briefing errors, failure to complete a full handover of resident information). Participants observed that it is also important for the system to track how nursing and care staff have addressed such changes. As stated by one participant, "to be effective, the technology needs to evaluate our responses to signals. This ensures that key response tasks are not omitted or forgotten".

Following from this, nursing participants noted that the proposed system might help bridge gaps between daily care, care planning and assessments. It was noted that care plans change, as the status of the resident changes. Often, care plans fail to reflect the current situation of the resident (i.e., fall behind resident changes), and/or, the latest feedback from assessments. In this regard, it was suggested that smart tracking of information about the resident arising from daily care activities (i.e., nurse/care giver feedback' and social activities, might be used to flag the requirement to undertake a new assessment and/or revise a care plan.

In relation to care requests, staff may receive in verbal care requests from residents outside their room location (i.e., not just using a call button). This needs to be considered in terms of contributing to resident wellness models and associated data analytics.

Some participants noted that the tablet might distract nursing staff from core communication/ care-giving activities (i.e., the nurse might become distracted scanning information and reporting on care tasks). This might impact negatively on resident interactions. Participants also expressed concerns that the introduction of an electronic rounding system might increase workload as opposed to reducing it. Further, participants queried whether such a tool might be used to justify a case for less staff (potentially increasing caregiver burden). In addition, participants expressed concern regarding the impact of such technologies on existing reporting processes (i.e., compliance). As highlighted by participants, it is quite common for nurses to undertake and report on care tasks at different times. As stated by one participant, "what happens if somebody in the next room is calling, and I am reporting my current check using the tablet? What should I do? Can I leave the reporting task until later?" Participants noted that from a practical perspective, the technology should not force nurses to report on rounding/resident checks at a fixed point in time.

\subsection{Needs and Requirements: Care Assistant}

Future systems might enable caregivers to report on tasks relating to managing resident ADL and resident requests. It was agreed that this would deliver significant benefits to the resident. Further, it was noted that care assistants are more likely to notice resident changes -specifically, changes in relation to mood and behavior and physical health (including skin changes). Thus, new systems might enable caregivers to report on wellness observations, to support the activities of nurses and clinicians. Further, such systems might enhance the communication between residents and care assistants, and between care assistants and the wider nursing/clinical team. It was also suggested that care assistants should have access to the residents' personal and social profile, to enhance communications both with residents and with family members.

\subsection{Needs and Requirements: Family Members}

For family members, future applications might enhance the feedback loop between residents, caregivers and family members. Specifically, family members might obtain information about the daily routines of their loved ones, key health and activity parameters (including both social and physical activity) and any changes. It was noted that although promoting contact with family members is good, this technology cannot mitigate negative family relationships. 
Family members also suggested that a separate system might be provided to elicit information about their loved ones, in advance of their being admitted to the residential home. Such a system might allow family members to input information about who the person is and what matters, care preferences, health status, allergies and past assessments.

\subsection{Needs and Requirements: Care Home Mangers/Owners}

Care home owners expressed a strong preference that this technology support health monitoring, resident safety, behavior management (i.e., identifying changes in behavior and potential for challenging behavior) and risk assessment (i.e., identifying/flagging fall risks, swallow risk and potential for self-harm or harm to others). It was also suggested that this technology might promote positive interactions between care/nursing staff and residents and purposeful engagement (for example, recording of resident personal/social profile and interests). It was agreed that this technology might also enhance social interaction (1) between residents, (2) between residents and their social network (i.e., friends and families) and (3) between residents and the wider community (i.e., maintaining links to volunteer groups and activities, and providing information about social events in the community).

\section{Proposed Concept and Technology Solution}

\subsection{Introduction}

This section presents the overall technology solution, as emerged in the iterative requirements specification, analysis and co-design activities. As mentioned previously, the initial technology concept and associated prototypes (i.e., prototypes for resident and other stakeholders) were advanced following an analysis of the findings of the literature review (research phases 1 and 2), and field research with older adults and other stakeholders (phase 3 research). These prototypes were further elaborated during co-design activities with internal and external stakeholders (research phases 6 and 7). First the overall concept and suite of applications is reported. Following this, the resident solution is outlined. A brief description of solutions for the nurse and care assistant are also provided. For more information on the proposed solutions for family members, pre-admissions, and admissions, please see $[25,26,41]$.

\subsection{Overall Concept and Applications}

The proposed functionality is conceptualized in relation to stakeholder relationships and enabling relationship-centered care. A suite of interrelated technologies has been advanced for older people and other stakeholders (i.e., nurses, care assistants, admissions/administration personnel and family members). Appendix A provides more information on the suite of applications and associated roles.

The frame of reference for the suite of solutions is the resident (and associated need, context and potential benefits). Solutions have been advanced for the resident (1) prior to transitioning to the residential home, (2) while undertaking the admissions process and, (3) to support daily life once domiciled in residential home.

In relation to (1), this involves a web interface that the older person/family member can access from home. Equally, the family member can use this on their own (assuming prior permission by the older adult). This system captures information about the resident to support the admission process. In relation to (2), the resident does not interact directly with this system. Rather, an Admissions Coordinator would use this system-sharing their screen with the resident and/or family member. Specifically, it is used to capture information about the resident to ensure a positive and safe transition to the residential home.

Overall the focus of this research has been in relation to (3). In this regard, the tablet solution and associated sensor kit has been advanced. Overall, the tablet solution and sensor kit supports the resident experience-enabling (a) residents, (b) family members and (c) all staff in the residential 
home to be involved in care. In relation to (c), this includes staff whose roles/responsibilities may not previously have been perceived as part of care delivery (for example, staff involved in pre-admissions, admissions, maintenance staff and concierge). It should be noted that (3) necessitates the advancement of complementary technology for other stakeholders (i.e., nurses, caregivers, family members). These are also outlined in more detail below.

\subsection{Resident Record}

The resident record is the starting point for enabling relationship-centered care. This captures relevant biopsychosocial information about the resident at different points in the care timeline. As defined in Figure 1 below, this information is derived both from the resident (i.e., inputs from the resident app and/or room sensors) and other actors (who use additional tablet solutions).

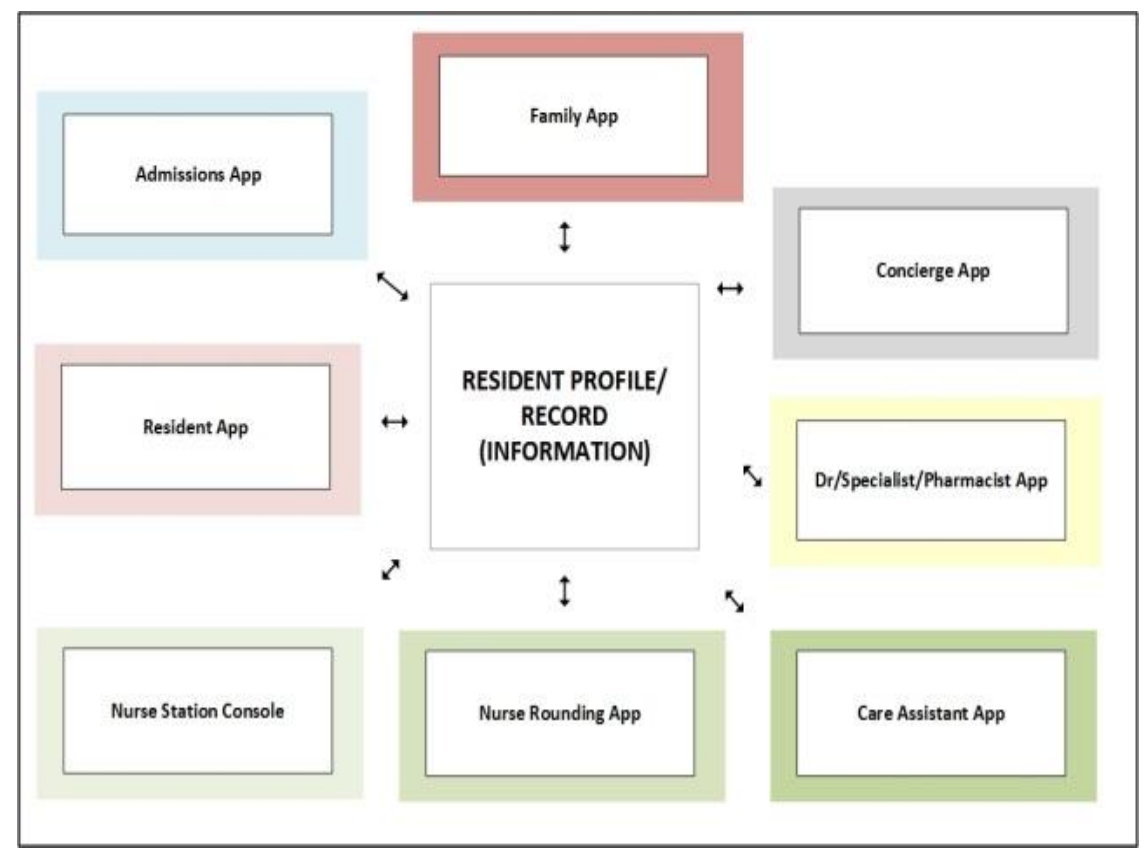

Figure 1. Stakeholders and Applications.

The resident record anchors the whole system, connecting the workflows of (1) pre-admissions/ admissions, (2) resident, (3) family members, (4) nursing staff, (5) care staff/nurse assistants, (6) concierge, (7) other medical staff, and (8) maintenance staff. In relation to the currency of this information, a distinction is drawn between (1) static information (i.e., name, gender, age, interests, social profile), (2) dynamic information (i.e., health profile, health assessments, events and activities, goals and education, club memberships), and (3) real-time information (i.e., current location, health status, mood, pain, social activity, medication, food orders).

\subsection{Resident Wellness: Biopsychosocial and Information Sources}

As indicated in Table 3 below, information pertaining to resident identity, wellness and ability is captured at different points in the care process (pre-admissions, admissions and real-time care), from all staff (i.e., caregivers, administration and concierge) using different tools as indicated above. This information is in turn integrated with data from sensors (for example, activity sensors, bed sensors) using a data triangulation process. In turn, the system can represent consistencies/inconsistencies across different data sources in relation to specific resident wellness parameters. For example, it can highlight that the resident is reporting good sleep to the nurse, but the bed sensor indicates that sleep 
has been poor. This information can be used to support more resident centered communications and uncover wellness problems.

Table 3. Resident information and Sources.

\begin{tabular}{|c|c|c|}
\hline Wellness Pillar & Type & Source \\
\hline \multirow{7}{*}{ Bio-medical } & $\begin{array}{l}\text { Health profile, ability, medications and } \\
\text { medical directives }\end{array}$ & Care Plan and Assessments \\
\hline & Diet and nutrition, modified diet and allergies & Care Plan and Assessments \\
\hline & Current Vitals/health status & Nurse report, health monitoring wearables \\
\hline & Daily care status & $\begin{array}{l}\text { Caregiver and nurse reports } \\
\text { Sensor-care calls, care visits }\end{array}$ \\
\hline & Medications status & Nurse report \\
\hline & Current physical activity & $\begin{array}{l}\text { Sensors—falls, bed } \\
\text { Self-reports } \\
\text { Caregiver and nurse reports }\end{array}$ \\
\hline & Current Frailty and ADL & $\begin{array}{l}\text { Caregiver and nurse reports } \\
\text { Sensors-activity, fall }\end{array}$ \\
\hline \multirow{9}{*}{ Social } & Communication ability & Care Plan and Assessments \\
\hline & Daily Routine & Personal Profile, Care Plan \\
\hline & Bio: personality and preferences & Personal Profile \\
\hline & Family and friends & Personal Profile \\
\hline & Interests and Activities, Club Memberships & Personal Profile \\
\hline & Current social activity—events/clubs & Events calendar (attendance, level of, change) \\
\hline & Current family visits (recent and upcoming) & $\begin{array}{l}\text { Family visits } \log \\
\text { Events calendar }\end{array}$ \\
\hline & Current visits outside & $\begin{array}{l}\text { Events calendar } \\
\text { Concierge requests (taxi, bookings) }\end{array}$ \\
\hline & Permissions (information sharing/access) & Admissions agreement \\
\hline \multirow{3}{*}{ Psychological } & Mood & $\begin{array}{l}\text { Self-report } \\
\text { Report from nurse/caregiver, family } \\
\text { Social activity (level of, change) } \\
\text { Sensor—nurse calls, activity }\end{array}$ \\
\hline & Behavior and challenging behavior & $\begin{array}{l}\text { Report from nurse, caregiver, family } \\
\text { Sensors-bed, activity } \\
\text { Care Plan and Assessments (triggers and } \\
\text { soothers) }\end{array}$ \\
\hline & $\begin{array}{l}\text { Bio: who you are and what matters, } \\
\text { important/meaningful dates, entertainment } \\
\text { preferences }\end{array}$ & Personal profile \\
\hline
\end{tabular}

\subsection{Resident Solution: Tablet and Sensor Kit}

\subsubsection{Overview}

The concept is to develop a range of self-decided services based on what matters to older people, and to allow for personalization (i.e., rights framework). The resident chooses what functions are available on the tablet and how they appear on the user interface. Equally, the resident chooses what sensors are used and how this information is distributed/used (i.e., privacy). For residents with cognitive impairment, this is negotiated between the resident, their family members and the care team. Importantly, the resident is involved in this decision-making.

The resident directly interacts with certain technology (for example, the resident tablet), while other technology is invisible (i.e., sensors). The primary interaction will be with the resident tablet device (touch interaction). This tablet device may or may not cast to the resident's in room TV. The design solution is adaptive in terms of age-related changes and characteristics. Interactions are 
natural using touch (and potentially speech and gesture). Currently, outputs are text/image-based. Research is currently addressing multimodal aspects (i.e., voice and gesture). Depending on the functional and cognitive ability of the resident, the resident may receive help using the tablet device (ability philosophy). In the case of a resident with early to mid-stage Dementia, the tablet features a reduced icon-based menu. Each menu item leads to a simplified user interface with picture-based content and functions. It is anticipated that the resident might interact with this interface (touch-based), with the help of their caregiver or family member. This promotes engagement and ability.

The resident home page features a series of menu items (text/icon-based) and notifications functionality. The resident can choose which menu items are most suitable, and if they would like notifications or not. As outlined in Appendix $\mathrm{H}$, the menu is grouped into nine overall functions/areas. This includes family and friends, social and events, care team, surveys, entertainment, my health, meals, concierge and room. There is also access to non-curated content (for example, Gmail, Google, Skype, YouTube and newspapers etc.). Figure 2 below illustrates an example customization with six menu items / functions.

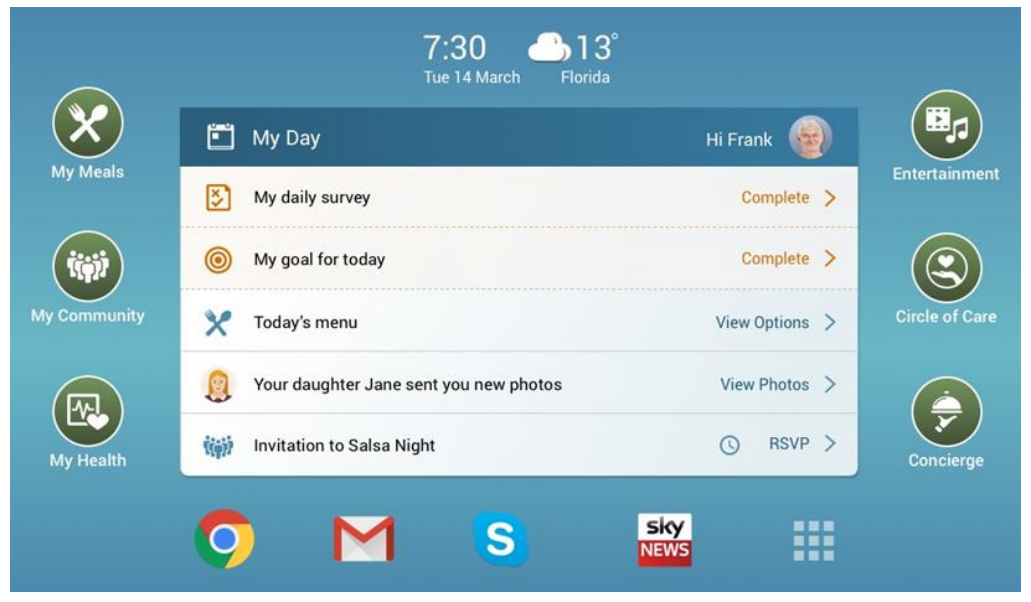

Figure 2. Resident Dashboard/Home Page.

Notifications can include a prompt to complete a survey, a reminder about a new video message from family/friends or a forthcoming visit, a reminder about a forthcoming club event that the resident is attending, or a suggestion to attend an event at the residential home/in the community that matches their interests (machine learning). A key feature is that the resident always receives a notification. This is underpinned by task activity (and associated processes) on the part of other roles at the residential home (i.e., Care Assistant, Entertainment Coordinator and Concierge). Moreover, this activity is supported by additional systems for other stakeholders. Certain tasks/functions will be automated by these systems, to mitigate staff workload. For example, the system can automate targeted reminders about GP appointments and club events, general emails to all residents providing information about a forthcoming event and the circulation of daily surveys.

Given that much of the environment is shared with others (for example, corridors, communal/social spaces, eating areas and outdoor areas), the "home" experience and allied issues of resident control is defined on two levels. This includes: (1) the resident's room, and (2) communal/social spaces. This is discussed in more detail in relation to the sensor kit below.

\subsubsection{Resident Solution and Key States}

The proposed technology addresses all three pillars of wellbeing and the interrelationship therein. Specific functions promote wellness and map to the underpinning biopsychosocial model of health and wellbeing. Overall, it considers models of successful ageing-supporting social participation, addressing stress, mood and engagement, providing entertainment functions and 
promoting self-management and purposeful ageing. In general, the resident solution promotes: (1) Identity, (2) Wellness, (3) Independent Living, (4) Communication, (5) Social Participation and Community Engagement and (6) Self-Management. More detailed information about these themes and the resident experience is provided in Table 4 below.

Table 4. Resident Experience and Technology Features.

\begin{tabular}{|c|c|c|}
\hline$\#$ & Theme & Resident Experience and Technology Features \\
\hline 1 & Identity, Rights and Control & $\begin{array}{l}\text { Technology elicits information about who the person is, } \\
\text { what matters, preferences-at different points in process } \\
\text { timeline } \\
\text { Person is active decision maker and consents to } \\
\text { devices/sensors } \\
\text { Access all personal and health information } \\
\text { Person involved in care/decisions } \\
\text { Control over who sees what information } \\
\text { Capture/record information about medical directives and } \\
\text { power of attorney }\end{array}$ \\
\hline 2 & Wellness (biopsychosocial) & $\begin{array}{l}\text { Wellness surveys } \\
\text { Free movement (monitoring not surveillance) } \\
\text { Engagement-social participation, activities } \\
\text { Relaxation/stress management } \\
\text { Sharing of wellness data with relevant actors (nurse, family) } \\
\text { Access to entertainment functions/information } \\
\text { Control over room settings }\end{array}$ \\
\hline 3 & Enabling Social Participation & $\begin{array}{l}\text { Buddy system } \\
\text { Social coaching re club events, residential home events, } \\
\text { events in wider community } \\
\text { Social profile-share with others } \\
\text { Focus on clubs and membership of community }\end{array}$ \\
\hline 4 & Communications with Family & $\begin{array}{l}\text { Communications with Circle of care } \\
\text { Sharing photos } \\
\text { Activity updates } \\
\text { Quick access to Skype } \\
\text { Notifications-new video message }\end{array}$ \\
\hline 5 & Communications with Care Team & $\begin{array}{l}\text { Beyond just emergency help } \\
\text { Getting information about care team today } \\
\text { Personalized messages (video/text) } \\
\text { Making care requests } \\
\text { Profile info (who are/what matters) available to care staff } \\
\text { (prime them about person and what matters) } \\
\text { Care team view recent social activity } \\
\text { Care team see surveys-how feeling/sleeping }\end{array}$ \\
\hline 6 & Taking control/independent living & $\begin{array}{l}\text { Access to health records and care plans } \\
\text { Meal ordering } \\
\text { Attending events } \\
\text { Concierge-order taxi, book hairdresser } \\
\text { Adjusting room settings } \\
\text { Capture/record information about medical directives and } \\
\text { power of attorney } \\
\text { Opt in/out sensors } \\
\text { Maintaining identity } \\
\text { Control over who sees what information }\end{array}$ \\
\hline 7 & Self-Management & $\begin{array}{l}\text { Notifications-biomarkers } \\
\text { Education and goals } \\
\text { Access to health records and care plans } \\
\text { Communicate about how feeling } \\
\text { Coaching in relation to attending events, planning activities }\end{array}$ \\
\hline
\end{tabular}


A large focus on the technology is on social participation and communication. The technology enables residents to report on mood and sleep, share their social and personal profile with other residents and care staff, report on social activity, register for events, share information with loved ones (i.e., photos and music), make Skype calls, and communicate with care staff (routine and emergency communications). Figure 3 provides an example of the daily survey (reporting on mood and sleep).

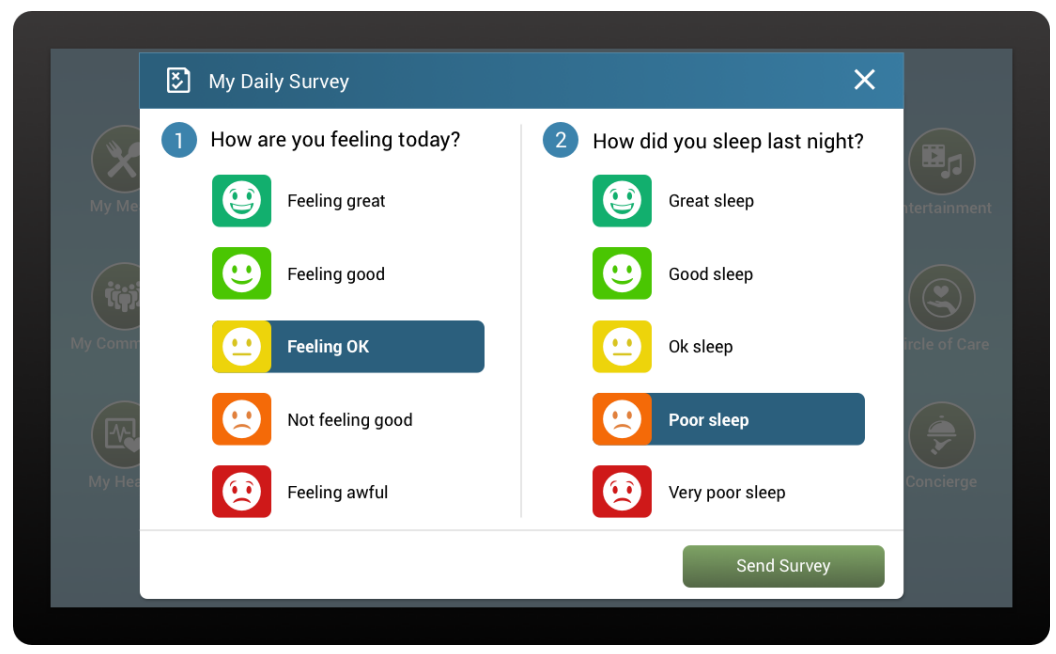

Figure 3. Daily Survey.

\subsubsection{Resident Sensor Solution and Ambient Technology}

A passive sensor solution has been advanced which forms part of the resident's environment. In terms of the resident's room, this includes passive infrared (PIR) activity-based sensors, bed sensors and sensors on doors and windows. All rooms will feature access controls and intuitive signage (pictures of residents and not just numbers). Smart lighting/heating will be implemented in resident rooms. Emergency call buttons will be located by the resident's bed, and in the bathroom. Pending resident/family agreement, residents may wear GPS insoles (i.e., enabling safe and free movement where there is a risk of wandering). These can be tied into proximity locks at restricted areas (i.e., doors would lock upon approach). Digital signage will be used in communal/social areas. It is anticipated that sensors will feature on all windows and doors around the facility. Real time location systems (RTLS) may be used (i.e., tracking resident/staff locations). There will be no CCTV. Lastly, there will be data analytics technology, monitoring and providing feedback about (1) resident wellness and activity (i.e., pain, sleep, falls, help requests, social activity, physical activity) and (2) staff activity (i.e., providing metrics in relation to care delivery / responses and feedback about the requirements for care assessments and revised care plans for specific residents).

The objective of the sensor kit is to provide safeguarding for the resident in their living area, track wellness indicators and provide predictive analytics to care teams based on the personal behaviors of the individual resident. Different sensor profiles can be assigned to residents at various stages of the care spectrum, to ensure that the sensors are in tune with the care needs of the resident. For example, if a resident has a history of manic behavior and the sensors detect that they are getting out of their bed at night and turning and off light switches, then this would be pertinent information for their care team to address this behavior before it escalates.

More general sensor profiles would address the issues of falls—at night, bed sensors and PIRs can observe that the resident has got out of bed. This event would turn on low-level lighting to the bathroom, to reduce the risk of a fall. The bathroom PIR would pick up that the resident has entered the bathroom. If the bedroom PIR and bed sensor do not pick up that the resident has returned to their bed within a time parameter, then a care event can be raised in case the resident has fallen (at a time they would be less likely to be wearing a pendant). 
Machine learning is utilized to refine the idea of "normal behavior" for the resident. For example, an individual may be accustomed to getting out of bed to sit at the window to pray at a particular time. This behavior would not need a care event to be raised (even though the resident may not have moved and has not returned to their bed).

\subsection{Nurse Checks/Rounding Solution}

The nurse rounding application is task-based and provides wellness notifications at different levels (i.e., summary and detailed). As indicated in Appendix I, an initial summary screen provides status information about all residents assigned to the nurse. Currently, this includes information about their type of care, whether rounded, mood, sleep, nurse calls and falls. All of this information is derived from resident reports and data analytics. In the future, this might flag additional information (for example, recent challenging behavior, pain, level of care contact and level of social engagement). The nurse selects a resident to view more detailed information and report on the resident round/check. As illustrated in Appendix J, this detailed view is structured in terms of a series of tabs: (1) status; (2) care plan and assessments; (3) profile; and (4) reports and analytics. The status tab includes summary information about the resident, rounding status, nurse concerns, self-reports, social activity, events and analytics, acute event and goals and education. The nurse interprets this data. The system does not prescribe what to do. The user interface design of the system is based on the aircraft cockpit philosophy (i.e., dark and silent). A traffic lights system provides notifications in relation to tasks outstanding and/or resident changes. The layout supports quick reading/information scanning. The system permits the nurse to save draft versions of a rounding report and complete reports at a later time.

\subsection{Care Assistant Solution}

The Care Assistant application allows caregiving staff to view information about the resident's current wellness, their activities, and their social and personal profile (i.e., who they are, what matters to them, and important calendar dates). The application also allows caregivers to report on their own task activities (i.e., support for ADL and care requests), and to provide feedback on the resident's mood and behavior. Further the system allows caregivers to communicate with nursing/clinical staff-reporting on any issues related to the resident safety and wellbeing, and specifically resident/family concerns.

\section{Discussion}

\subsection{Summary of Study Purpose and Key Findings}

As defined earlier, the overall purpose of this study is to identify and validate the requirements for new technology supporting wellness, independence and social participation for older people domiciled in residential homes and/or assisted-living communities. Table 5 below provides a summary of the key findings. These findings are discussed in more detail below.

Table 5. Summary of Key Findings.

\begin{tabular}{cl}
\hline$\#$ & \multicolumn{1}{c}{ Summary of Key Research Findings } \\
\hline 1 & $\begin{array}{l}\text { Overall, participants expressed a preference for older people to remain in their own } \\
\text { homes and that future AL technology might follow certain trends in terms of what is } \\
\text { used in the home }\end{array}$ \\
\hline 2 & Ageing is multidimensional and includes psychosocial elements \\
\hline 3 & Participants agreed that new technology should reflect positive values around ageing \\
\hline 4 & $\begin{array}{l}\text { Participants agreed that technology should be underpinned by concepts of relational } \\
\text { autonomy, relationship-centered care and biopsychosocial concepts of wellness }\end{array}$ \\
\hline
\end{tabular}


Table 5. Cont.

\begin{tabular}{cl}
\hline$\#$ & \multicolumn{1}{c}{ Summary of Key Research Findings } \\
\hline 5 & $\begin{array}{l}\text { Participants agreed that the design of new technology should reflect a careful balance } \\
\text { between organizational goals and resident needs and ability }\end{array}$ \\
\hline 6 & $\begin{array}{l}\text { It was agreed that the design remit for this technology is to enable a resident } \\
\text { experience which is similar to "living in one's own home" }\end{array}$ \\
\hline 7 & Technology should be customized to resident need and ability \\
\hline 9 & Technology should promote resident wellness, independence and social participation \\
\hline 10 & $\begin{array}{l}\text { Participants agreed that new technology should take into account ethical issues } \\
\text { technology should not negatively impact on the frequency and quality of human } \\
\text { contact with caregivers and family members }\end{array}$ \\
\hline 11 & $\begin{array}{l}\text { The introduction of new technology requires the parallel implementation of new } \\
\text { processes to address issues pertaining to human contact }\end{array}$ \\
\hline 12 & $\begin{array}{l}\text { New technology provides an opportunity to bridge information gaps between care } \\
\text { planning, care assessments and daily care }\end{array}$ \\
\hline 14 & $\begin{array}{l}\text { New technology affords the possibility for improved social relationships, better quality } \\
\text { of care and user control/independence in residential care contexts. }\end{array}$ \\
\hline & $\begin{array}{l}\text { It is not likely that residents with mid to late-stage dementia will have significant } \\
\text { interaction with Tablet/TV systems. Solutions for other stakeholders (family, } \\
\text { nurses and care staff) will yield benefits for such residents. }\end{array}$ \\
\hline
\end{tabular}

\subsection{New Approach and Addressing Gaps}

This research provides a roadmap for the implementation of future technology in assisted-living contexts. Critically, the proposed concept and associated user interface design solution is (1) premised on human factors research pertaining to stakeholder need, technology requirements and benefits. Further, it is (2) underpinned by relevant theory. In addition, the proposed solution (3) directly addresses key issues concerning resident rights, issues of user acceptability and specific issues pertaining to social participation and human contact.

In relation to (1), the emerging concept is predicated stakeholder evaluation research, using best practice human factors/HMI design methods. The specification of need/requirements does not fall short of design instruction. Specifically, the use of co-design techniques bridges the gap between requirements elicitation (i.e., user interviews and observations), requirements specification and user interface design. Further, the use of co-design techniques has enabled problem solving/evaluation in relation to ethical issues and issues of user acceptability.

In relation to (2), this new approach positively addresses the gaps in existing research in relation to providing a principled and theoretical basis for technology design. Firstly, the technology solution is conceptualized in relation to concepts of relational autonomy and relationship-centered care. These concepts provide the conceptual framework for thinking about need, and associated concepts of independence, quality of life and social participation. Overall, the approach is to develop technology from the perspective of understanding the social relationship and interdependencies between different stakeholders. These relationships and interdependencies are modeled in terms of information flows, which contribute to an overall picture of resident wellness. This ensures that the states/lived experience outlined in Table 2 are positively addressed [31,32,47]. Critically, the technology enables all actors to be involved in delivering care to older adults. Further, the proposed technology provides functions which link to all three wellness pillars (i.e., biological, psychological and social) [1,2]. Certain individual functions directly link to specific wellness pillars (for example, communication functions and social wellness). However, to promote positive states of wellbeing for residents, the overall solution needs address all three pillars of wellbeing. Moreover, in keeping with models of successful ageing, 
the proposed technology enables psychosocial occupation and social connection, while also addressing resident safety.

In relation to (3), this research directly tackles issues of resident rights and user acceptability. Further, it addresses existing gaps in the literature specifically pertaining to social participation and human contact. As indicated with field research with older adults and other stakeholders, the advancement of assistive technology raises overarching questions in relation to the values of society and how the design of future technologies both reflects and upholds these values [47]. In particular, this includes questions about (a) the value we place on promoting autonomy, wellbeing and social participation for older adults and (b) protecting resident dignity and privacy. Overall, the technology should be designed to promote positive values around ageing [47]. The proposed technology must enhance the ageing experience and deliver positive outcomes in terms of how residents live in residential settings. In keeping with the literature, the technology needs to support resident independence [15], social connection [21,23], and physical liberty [16,17]. In line with expressions of rights for older people domiciled in residential homes $[27,28]$, and the European convention on human rights [29], new systems should respect an older adult's privacy and choice. The older person must be the "driving seat" —opting in and out of all services, as required (promoting independence and quality of life). Residents should have control over their personal sphere, including any information captured about the biopsychosocial dimensions of their health and wellbeing.

This research indicates that future systems should not be used to replace person-centered care and/or to reduce the time that nursing and care staff spend with their patients. Further, it should reflect a careful balance between optimizing the ability/strengths of the person while considering the needs (and workload) of caregivers. As noted previously, all participants expressed concern that the introduction of this technology might lead to (a) a reduction in human contact, and (b) poor quality human contact. Further, as reported earlier, participants raised concerns that in person contact would no longer be routine/the cornerstone of care processes. As humans, we need companionship and social connection. This is an issue for all residents. However, it is particularly salient, for those residents with limited social ties, reduced mobility, poor health (i.e., confined to bed) and those with communication difficulties (i.e., mid to late-stage dementia). As highlighted earlier, the incidence of clinical errors resulting in patient harm and/or mortality is higher for older adults and those with poor communication ability (i.e., persons with disability and/or cognitive impairment). Further, the presence of family members (i.e., care advocates) has an impact on care. Those with reduced or no social ties/family participation are potentially more at risk. Overall the goal is to enhance the quality of care by providing all staff with the right information at the right time. Specifically, the objective is to use the technology to inform those actors who have leverage over addressing/managing the problem. This is critical in relation to issues around highlighting (1) deteriorations in resident physical, mental, social and emotional health, (2) self-neglect and/or harm, (3) poor quality care and/or abuse, and (4) resident safety. For example, in relation to (1), the technology should be used to identify resident issues in relation to social participation. Accordingly, it should generate prompts for Entertainment Coordinators to set up purposeful resident activities and/or to prompt families to visit. The technology should also be used to boost or act as a trigger for "face-to-face" interaction (i.e., provision of social profile, membership of clubs, reminders of events). In this way, it can be used to bring people together around common interests (i.e., being in a club, sharing information about club events, sharing photos, sharing stories). Further, the technology might also be used to track what activities the resident enjoys or finds purposeful-learning about the resident to improve care.

Questions of automation are specifically salient in relation to reporting on lived experience (i.e., reporting on sleep, mood and pain). The nurse may have received this information (i.e., computer mediated). However a meaning conversation still needs to occur between the resident and nursing/care staff. Survey feedback becomes an interaction prompt. "I see from your sleep survey that you did not sleep very well. How are you feeling now?" The technology is about improving the 
information picture (triangulation of information from different sources), not removing meaningful contact/communication. As such, the technology changes the starting point for this conversation.

In relation to evaluating the quality of care, the technology can track time spent with the resident. Evidently, this metric does not indicate quality of care. For example, staff may be in the room, but they may not be interacting with the resident. However, it is a useful starting point. Potentially a future technology implementation might provide feedback/analytics in relation to evaluating the quality of care delivery. That is, the technology might be used to monitor and evaluate human contact-flagging risks in relation to poor quality human contact/communications (i.e., superficial communication, lack of care, lack of compassion and abuse).

\subsection{AL Technology: Solving Problems only to Introduce others}

The proposed technology is predicated on addressing specific states associated with resident independence, wellbeing, quality of life and social participation. However, the introduction of new technology to address these states can inadvertently create new problems. Conceptually, two related issues can be defined. Firstly, the introduction of new technology to optimize a given resident state (for example, independence/ability) can occur at the expense of other states (for example, social participation/loneliness). For example, there is a potential risk that reduced social contact (and potentially loneliness/isolation), becomes a byproduct of this technology. The tablet allows the resident to undertake certain tasks (previously requiring human assistance) without the help of nursing/care staff (i.e., meal ordering, transport coordination, switching on the TV, turning on/off lights, adjusting heating, requesting room cleaning and do not disturb requests). Interacting with a nurse or caregiver is replaced with interacting with a tablet. Although the older person is enabled, it comes at a real cost. As reported by participants, the face-to-face social interaction/conversation, which once formed part of this task, is now removed. Potentially, over the course of a day, several opportunities to communicate face to face with another person are lost. Importantly, the other communications, which follow from such care requests, are also lost. For example, while taking a meal order, a caregiver has the opportunity to ask the resident how they are feeling or enquire about social activities and/or family visits.

As such, in introducing new technology, we need to be mindful of how the technology can generate positive outcomes for certain resident states, while simultaneously creating negative outcomes in relation to other states. The introduction of new technology is task-based. Specific technology functions address unique tasks (i.e., resident meal ordering) and often link to single states (i.e., independence) and/or a subset of states. Thus, the implementation of a specific technology function cannot address all states simultaneously. However, the implementation should consider the advancement of other technology functions which might mitigate the potential negative states/outcomes arising from a given technology function. This includes a consideration of technology for (1) residents and (2) other roles that interact with residents (both directly and indirectly). Moreover, the total technology solution should be evaluated in relation to addressing all relevant resident states (holistic perspective) - bearing in mind the technology delivery both for residents and other relevant roles.

Secondly, the use of new AL technologies will unavoidably lead to behavior change for residents and other roles. New task practices and/or communication norms will arise. As such, we are designing new ways of being (ontological design). From a human perspective, such innovation does not always result in better ways of doing things. In transforming task practices (i.e., promoting independence and introducing task efficiencies for care staff), we may change some fundamental aspects of what it means to be human, to communicate and to provide care. For example, as noted by participants, the provision of Skype functionality makes it easier for residents to stay in touch with family and friends. However, making a Skype call or sending a wave/photo to a loved one, does not replace in-person communication. Further, if such communications becomes established (i.e., the new norm), then this has the potential to have a more far-reaching impact. Potentially, the provision of Skype will result in less in person visits. Thus, the behavior change, which arises from the introduction of 
this new technology, has consequences for resident wellbeing/quality of life. The technology enables and fosters one form of communication (i.e., virtual communication) at the expense of the other (i.e., in person communication).

\subsection{Transforming Care through Improving Information Flows between Care Planning, Assessments and Daily Care}

This technology provides an opportunity to bridge information gaps between care planning, care assessments and daily care. The initial care plan is derived from (1) inputs from the resident and/or family members in relation to resident need, what matters to the resident and typical daily routine/habits and (2) the outcome of relevant assessments (i.e., activities of daily living/functional independence, nutrition, medication, cognitive, social and behavioral). Once in the system, this picture can be both validated and strengthened, in relation to eliciting information from daily care (i.e., information gleamed from nursing and care personnel, and from resident and family feedback), and establishing a baseline for the person (i.e., what is normal/what is a change from normal indicating something to be checked). To improve care, we need to ensure that these information flows are both integrated and current. This information flow is bi-directional. Daily care information can be used to set the schedule for assessments (i.e., taking into account resident changes and not merely compliance requirements). Further, information from assessments can be funneled to caregivers to support both care planning and daily care. Moreover, real-time inputs (i.e., care concerns and rounding observations) from relevant roles (i.e., nurses, caregivers, resident's/family member) can be acted on immediately. Critically, this technology generates evidence to support clinical decision-making in relation to resident wellness and the requirement to undertake new assessments and/or revise care plans. Insofar as this technology transforms this process (i.e., flagging nurse/family concerns and highlighting wellness changes), it improves care.

5.5. Human Role in Relation to Technology and Requirement for New Processes to Mitigate Issues Pertaining to Loss of Social Contact

Some of the human factors issues raised by the introduction of this new technology may not be solved by the advancement of complementary technology designed to mitigate potential negative outcomes for the resident (i.e., other resident technology and/or technology for other roles). Rather, the problems may require redefinition of the human role in relation to technology usage and specifically, other socio-technical interventions. This includes new care processes/procedures, staff training, care culture interventions and so forth.

\subsection{Study Limitations}

As noted previously, this is an action research study. The requirements elicitation and solutions space is vast. In this regard, the initial requirements elicitation and co-design activities have focused primarily on the resident solution. Solutions for other stakeholders (i.e., admissions coordinator, nurses, care assistants and family members) have been addressed in relation to delivering resident benefits. These solutions require further definition.

Certain limitations regarding the composition of the participant panel should be noted. Interviews with older adults $(N=11)$ involved the participation of 10 females and 1 male. It would be useful to obtain additional insights from older males. Two participants were classified as active and healthy, $6 \mathrm{had}$ one or more morbidities and 3 had some level of functional decline. Of the eleven participants, one was in receipt of formal care supports in the home, while four others depended on informal supports in the home (i.e., help from family and friends). The panel did not include older persons domiciled in residential homes. However, nurses and family members provided indirect feedback in relation to the perspective of such residents. Co-design activities involved the participation of older adults, but not actual care home residents. Currently, ageing experts and family members have provided feedback in relation to the needs of older adults with diverse physical/functional and 
cognitive abilities. Additional research is required with older adults with diverse age related physical (i.e., sight, motor and auditory challenges) and cognitive challenges (i.e., early cognitive decline and/or dementia). As stated earlier, it is anticipated that some of the above challenges will be considered in research phases 8 and 9 .

The initial observations were not that extensive. More detailed observations of care delivery and resident experiences are required. The proposed solution has not been implemented in a care setting (i.e., ecological validity). The elicitation of implementation feedback (i.e., user/stakeholder feedback predicated on product interaction over a period of time) is a key human factors design/evaluation activity. Such feedback offers insights into what is actually acceptable to end users, how end users actually use the product, usability issues and constraints. Further, it provides information regarding implementation challenges at an organizational level (including process change, resourcing and capacity and cultural issues). This feedback is necessary to validate the solution. It is anticipated that the proposed assisted-living (AL) product will go live with customers during the lifecycle of this project. Depending on the implementation timeline, evaluations will be undertaken with residents, care staff, nurses and family members. Such feedback will be used to strengthen the ecological validity and usability of the final solution.

\section{Conclusions}

This study indicates that resident autonomy, social participation and quality of life cannot be conceptualized outside an understanding of the partnerships older people have in their personal and professional community. Accordingly, the approach is to develop technology that promotes resident ability, wellness and rights, and is premised on supporting relationships between different stakeholders. New technologies have been developed to support communication/community dwelling and not simply risk assessment. These technologies enable a resident experience that is similar to "living in one's own home". As indicated in this study, new assisted-living technology can promote social connection and enhance relationships/communications. However, it is not a solution to loneliness. This study suggests that there is a potential risk that reduced social contact (and potentially loneliness), may become a byproduct of this technology. This is a key challenge to be addressed. New processes/procedures might be introduced to mitigate the potential loss of social contact arising from the introduction of this technology and to ensure that the fundamentals of person centered care delivery are not compromised.

Acknowledgments: This study has been sponsored by Oneview Healthcare, Ireland. The funding includes covering the costs to publish in open access.

Author Contributions: Joan Cahill conceived, designed, performed and analyzed the data; Sean McLoughlin and Sean Wetherall provided feedback in relation to market and user need, and the sensor technology solution. Sean McLoughlin is the product owner on behalf of Oneview Healthcare and has coordinated the feedback of human factors research to the product development team.

Conflicts of Interest: The authors declare no conflict of interest. The founding sponsors had no role in the design of the study; in the collection, analyses, or interpretation of data; in the writing of the manuscript, and in the decision to publish the results.

\section{Appendix A.}

Table A1. Summary of Applications.

\begin{tabular}{ccccc}
\hline$\#$ & Process & Actor & Application and Device & \multicolumn{1}{c}{ Description } \\
\hline & & & & $\begin{array}{l}\text { Resident and /or loved one provides } \\
\text { background information about the } \\
\text { resident-social and personal profile, } \\
\text { health status, prior assessments and ability. }\end{array}$ \\
\hline
\end{tabular}


Table A1. Cont.

\begin{tabular}{|c|c|c|c|c|}
\hline \# & Process & Actor & Application and Device & Description \\
\hline 2 & Admissions & $\begin{array}{l}\text { Admissions } \\
\text { Co-coordinator }\end{array}$ & $\begin{array}{l}\text { Admissions App (Desktop } \\
\text { Computer and Tablet) }\end{array}$ & $\begin{array}{l}\text { The admissions application is used to complete } \\
\text { the resident profile picture, at the time of } \\
\text { admissions. Prior information provided at the } \\
\text { preadmissions stage is prepopulated in the } \\
\text { system. The admissions user interface is } \\
\text { conceptualized in terms of a series of steps to } \\
\text { promote familiarization for both residents and } \\
\text { care staff, and reassurance for residents and } \\
\text { family members. }\end{array}$ \\
\hline 3 & $\begin{array}{l}\text { Assessments } \\
\text { and Care } \\
\text { Planning }\end{array}$ & Nurse & $\begin{array}{l}\text { Assessments App } \\
\text { (Desktop Computer) }\end{array}$ & $\begin{array}{l}\text { This records resident assessments } \\
\text { information-comprising general wellness, } \\
\text { nutrition, activities of daily living and } \\
\text { functional ability, cognitive, behavioral etc. }\end{array}$ \\
\hline \multirow{5}{*}{4} & \multirow{5}{*}{ Daily Care } & Resident & Resident App (Tablet) & $\begin{array}{l}\text { The resident solution is customized in relation } \\
\text { to resident need and ability. } \\
\text { The resident can select from a series of } \\
\text { functions-based on need/interest. } \\
\text { Residents with mid to late-stage dementia-are } \\
\text { not expected to interact directly with tablet } \\
\text { system (require assistance). }\end{array}$ \\
\hline & & Nurse & Nurse Rounding App (Tablet) & $\begin{array}{l}\text { The nursing solution promotes meaningful } \\
\text { interaction with the resident, based on a real } \\
\text { time picture of the resident's state, } \\
\text { and background information about who the } \\
\text { resident is and what matters to them. } \\
\text { This application is also used to record } \\
\text { rounding information-structured from } \\
\text { biopsychosocial perspective. }\end{array}$ \\
\hline & & Care Assistant & Caregiver App (Tablet) & $\begin{array}{l}\text { This care assistant application enables } \\
\text { reporting on ADL and caregiving tasks-it also } \\
\text { provides access to information about the } \\
\text { resident-personal history, what matters. }\end{array}$ \\
\hline & & Nurse Manager & Care Console (Desktop Computer) & $\begin{array}{l}\text { Supports queries/data analytics in relation to } \\
\text { resident wellness, assessments, activity and so } \\
\text { forth. Also provides real-time information } \\
\text { about the resident. }\end{array}$ \\
\hline & & Family & Family App (phone, web) & $\begin{array}{l}\text { This allows the family member to view } \\
\text { relevant real time and historical information } \\
\text { about their loved one. Used also to upload } \\
\text { content/information etc. }\end{array}$ \\
\hline 5 & Maintenance & Maintenance & $\begin{array}{l}\text { Maintenance Managements } \\
\text { (Desktop and Tablet) }\end{array}$ & $\begin{array}{l}\text { This application is used to process and manage } \\
\text { maintenance requests from residents and staff. }\end{array}$ \\
\hline 6 & $\begin{array}{l}\text { Resident } \\
\text { Activities and } \\
\text { Entertainment }\end{array}$ & $\begin{array}{l}\text { Entertainment } \\
\text { Coordinator }\end{array}$ & Event Managements (Desktop) & Manage resident social activities and events. \\
\hline 7 & Concierge & Concierge Manager & Concierge (Desktop) & $\begin{array}{l}\text { Manage resident requests (i.e., travel, room } \\
\text { maintenance etc.). }\end{array}$ \\
\hline
\end{tabular}

\section{Appendix B. Research Milestones}

Table A2. Research Milestones.

\begin{tabular}{cccll}
\hline$\#$ & Dates & Research Phase & \multicolumn{1}{c}{ Description } & \multicolumn{1}{c}{$\begin{array}{c}\text { Input to Product } \\
\text { Development }\end{array}$} \\
\hline M1 & End December 2016 & 1 & $\begin{array}{l}\text { Product analysis and problem } \\
\text { statement signoff }\end{array}$ & $\begin{array}{l}\text { Summary of approach and } \\
\text { personae 1 }\end{array}$ \\
\hline M2 & End February 2017 & 3 & Ethics application submitted & \\
\hline M3 & End June 2017 & 3 & Initial user research completed & \\
\hline M4 & End July 2017 & 4 & $\begin{array}{l}\text { Specification of high-level concept, } \\
\text { requirements, demo scenarios and } \\
\text { expected benefits }\end{array}$ & $\begin{array}{l}\text { Personae 2 } \\
\text { High level user } \\
\text { requirements }\end{array}$ \\
\hline M5 & End August 2017 & 5 & $\begin{array}{l}\text { Production of initial version 1 } \\
\text { prototype for use in } \\
\text { co-design activities }\end{array}$ & Prototype 1 \\
\hline M6 & End October 2017 & 6 & $\begin{array}{l}\text { Production of Version 2 prototype } \\
\text { following co-design activities }\end{array}$ & Prototype 2 \\
\hline
\end{tabular}


Table A2. Cont.

\begin{tabular}{ccclc}
\hline$\#$ & Dates & Research Phase & \multicolumn{1}{c}{ Description } & $\begin{array}{c}\text { Input to Product } \\
\text { Development }\end{array}$ \\
\hline M7 & End January 2018 & 7 & $\begin{array}{l}\text { Production of Version 3 prototype } \\
\text { following co-design activities }\end{array}$ & Prototype 3 \\
\hline M8 & End May 2018 & 8 and 9 & $\begin{array}{l}\text { Production of Version 4 prototype } \\
\text { following co-design activities }\end{array}$ & Prototype 4 \\
\hline M9 & End September 2018 & 10 & $\begin{array}{l}\text { Version 5 prototype (final prototype) } \\
\text { following co-design activities and } \\
\text { living lab evaluation/feedback }\end{array}$ & Prototype 5 \\
\hline
\end{tabular}

\section{Appendix C. Composition of COP (External and Internal Stakeholders)}

Table A3. Composition of Community of Practice (External and Internal Stakeholders).

\begin{tabular}{|c|c|c|c|c|}
\hline Stakeholder Type & Group & Total & Description/Sub Group & \# \\
\hline \multirow{19}{*}{ External } & \multirow{4}{*}{ Older People } & \multirow{4}{*}{11} & $\begin{array}{l}\text { A. Active and healthy seniors aged between } 60 \\
\text { and } 75 \text {. Living in own homes-fully } \\
\text { independent. Healthy. }\end{array}$ & 3 \\
\hline & & & $\begin{array}{l}\text { B. Seniors aged between } 70 \text { and } 85 \text {. Potentially } \\
\text { living with one or more morbidities. Living in } \\
\text { own home. May or may not have some level of } \\
\text { care (formal/informal). }\end{array}$ & 5 \\
\hline & & & $\begin{array}{l}\text { C. Frail elderly aged between } 70 \text { and } 90 \text {. } \\
\text { Functional decline-mobility issues. May or } \\
\text { may not have mild cognitive impairment/early } \\
\text { cognitive decline. Living in own home. May or } \\
\text { may not have some level of care } \\
\text { (formal/informal). }\end{array}$ & 3 \\
\hline & & & $\begin{array}{l}\text { D. Seniors living in residential homes aged } \\
\text { between } 70 \text { and } 90 \text {. Potentially living with one } \\
\text { or more morbidities. Potentially, some level of } \\
\text { functional decline. May or may not have early } \\
\text { cognitive decline }\end{array}$ & 0 \\
\hline & Family & 7 & & \\
\hline & Ageing/Dementia Experts & 5 & & \\
\hline & Ageing/ICT Experts & 1 & & \\
\hline & \multirow{3}{*}{ Nurses } & \multirow{3}{*}{4} & Community Nurse & 2 \\
\hline & & & Nurse/GP Service & 1 \\
\hline & & & Nursing Director/Nursing Homes Ireland & 1 \\
\hline & $\begin{array}{c}\text { Care for Older People Day } \\
\text { Service (1) }\end{array}$ & 1 & Nurse Manger & 1 \\
\hline & \multirow{4}{*}{$\begin{array}{c}\text { Care for Older People Day } \\
\text { Service (2) }\end{array}$} & \multirow{4}{*}{4} & Nurse Manager & 1 \\
\hline & & & Nurse & 1 \\
\hline & & & Pharmacist & 1 \\
\hline & & & Dietician & 1 \\
\hline & \multirow{2}{*}{ Post- Acute Care } & \multirow{2}{*}{3} & Geriatrician & 1 \\
\hline & & & Nurse & 2 \\
\hline & \multirow{2}{*}{ Residential Care } & \multirow{2}{*}{2} & Owner & 1 \\
\hline & & & Entertainment Co-ordinator & 1 \\
\hline \multirow{6}{*}{ Internal } & Product Owner & 1 & & \\
\hline & ICT Ageing & 2 & & \\
\hline & ICT Ageing/Nurse & 2 & & \\
\hline & Graphic Designer & 2 & & \\
\hline & Health Informatics/Dr & 1 & & \\
\hline & Total & 47 & & \\
\hline
\end{tabular}




\section{Appendix D. Theory and High Level Functions/Requirements}

Table A4. Theory and High level functions/requirements.

\begin{tabular}{|c|c|c|c|c|c|}
\hline Process & High Level Function & Model of Successful Ageing & Biopsychosocial Model & $\begin{array}{l}\text { Stakeholder } \\
\text { Relationships }\end{array}$ & $\begin{array}{l}\text { States/Benefits (1) Promote, } \\
\text { (2) Manage/Mitigate and } \\
\text { (3) Avoid }\end{array}$ \\
\hline Daily Routine/Life & $\begin{array}{l}\text { Social engagement } \\
\text { and events }\end{array}$ & $\begin{array}{l}\text { Social functioning, leisure activities, integration and } \\
\text { participation in social/community activity, personal } \\
\text { growth, active engagement with life (including } \\
\text { maintenance of autonomy and social support) }\end{array}$ & Social and psychological & $\begin{array}{l}\text { Senior, carer, family, } \\
\text { friends, neighbors \& GP }\end{array}$ & $\begin{array}{l}\text { Promote sense of purpose, social connection, sense of } \\
\text { usefulness, citizen participation } \\
\text { Manage/mitigate: boredom, loneliness, depression } \\
\text { Avoid: isolation, reduction in human contact }\end{array}$ \\
\hline
\end{tabular}

\section{Appendix E. Older Adults: Participant Profiles}

Table A5. Older Adults-Participant Profiles.

\begin{tabular}{|c|c|c|c|c|c|c|c|c|c|c|c|c|c|c|}
\hline$\#$ & Long/Short & Category & $\mathbf{M} / \mathbf{F}$ & Age & $\begin{array}{l}\text { Lives } \\
\text { Alone }\end{array}$ & Home-Independent & $\begin{array}{l}\text { Home-Needs } \\
\text { Help from } \\
\text { Informal Carer }\end{array}$ & $\begin{array}{l}\text { Home-Needs } \\
\text { Help from } \\
\text { Formal Carer }\end{array}$ & $\begin{array}{l}\text { Home-Providing } \\
\text { Informal Care for } \\
\text { Ageing/Ill Partner }\end{array}$ & FC & CD & Use PC & Use Mobile & User Internet \\
\hline 1 & Short & A & $\mathrm{F}$ & 75 & Yes & Yes & No & No & $\begin{array}{c}\text { Yes_-since passed } \\
\text { away }\end{array}$ & No & No & Yes-proficient & Yes-proficient & Yes-proficient \\
\hline 2 & Short & B & $\mathrm{F}$ & 84 & Yes & Yes & No & No & No & No & No & Yes_-basic & Yes_-basic & $\begin{array}{c}\text { Yes—for } \\
\text { Skype only }\end{array}$ \\
\hline 3 & Short & B & $\mathrm{F}$ & 81 & Yes & Yes & No & No & No & No & No & Yes_basic & Yes_basic & $\begin{array}{c}\text { Yes-for } \\
\text { Skype only }\end{array}$ \\
\hline 4 & Long & B & $\mathrm{F}$ & 80 & Yes & Yes & No & No & No & Yes & No & Yes_-proficient & Yes-proficient & Yes_proficient \\
\hline 5 & Long & C & $\mathrm{F}$ & 84 & Yes & Yes & Yes & No & $\begin{array}{c}\text { Yes—since } \\
\text { passed away }\end{array}$ & Yes & $\begin{array}{c}\text { Yes } \\
\text { (ECD) }\end{array}$ & No & Yes_-basic & $\begin{array}{c}\text { Yes-needs help } \\
\text { for Skype }\end{array}$ \\
\hline 6 & Long & B & $\mathrm{M}$ & 81 & Yes & Yes & Yes & No & $\begin{array}{c}\text { Yes—-since } \\
\text { passed away }\end{array}$ & No & No & Yes-basic & Yes-basic & Yes-basic \\
\hline 7 & Long & A & $\mathrm{F}$ & 70 & Yes & Yes & No & No & Yes-with Dementia & No & No & Yes_-basic & Yes_-basic & Yes_-basic \\
\hline 8 & Long & A & $\mathrm{F}$ & 74 & Yes & Yes & No & No & No & No & No & No & Yes—basic & Yes—basic \\
\hline 9 & Long & C & $\mathrm{F}$ & 89 & Yes & No & Yes & Yes & No & Yes & $\begin{array}{c}\text { Yes } \\
\text { (ECD) }\end{array}$ & No & Yes-basic & $\begin{array}{c}\text { Yes-needs help } \\
\text { for Skype }\end{array}$ \\
\hline 10 & Long & B & $\mathrm{F}$ & 77 & Yes & Yes & No & No & No & No & No & No & Yes-basic & Yes-basic \\
\hline 11 & Long & $\mathrm{C}$ & F & 78 & Yes & Yes & Yes & No & No & Yes & No & Yes_basic & Yes_basic & Yes-basic \\
\hline
\end{tabular}

$\mathrm{FD}=$ functional decline, $\mathrm{CD}=$ cognitive decline, $\mathrm{ECD}=$ early cognitive decline. 


\section{Appendix F. Data/Coding Frame}

Table A6. Data/Coding Frame.

\begin{tabular}{|c|c|c|c|}
\hline Research Question & $\#$ & $\begin{array}{l}\text { Parent Node/Category (Key } \\
\text { Concepts of Analysis) }\end{array}$ & Child Node: Subcategory \\
\hline Lived experience of being old & 1 & Lived experience of being old & $\begin{array}{c}\text { Home Setting } \\
\text { Residential Setting } \\
\text { Biopsychosocial } \\
\text { Relational autonomy } \\
\text { Social participation } \\
\text { Quality of life } \\
\text { Meaning of life } \\
\text { Ageism }\end{array}$ \\
\hline Concepts of care & 2 & Concepts of Care & $\begin{array}{l}\text { Relationship centered care } \\
\text { Person centered care }\end{array}$ \\
\hline How is care provided in different settings? & 3 & Care Approaches and Settings & $\begin{array}{c}\text { Home-independent } \\
\text { Home-care givers } \\
\text { Community Monitoring } \\
\text { Dementia care } \\
\text { Residential Home } \\
\text { Residential Community } \\
\text { Palliative }\end{array}$ \\
\hline Care Settings and Issues to Be Addressed & 4 & Care Settings/Issues & $\begin{array}{c}\text { Home-independent } \\
\text { Home-care givers } \\
\text { Community Monitoring } \\
\text { Dementia care } \\
\text { Residential Home } \\
\text { Residential Community } \\
\text { Palliative }\end{array}$ \\
\hline Acceptability of AL Technology & 4 & Acceptability & \\
\hline New Tech and States of being & 5 & New Tech and States of being & $\begin{array}{l}\text { States to be achieved } \\
\text { States to be managed/mitigated } \\
\text { States to be avoided }\end{array}$ \\
\hline New Technology and Themes & 6 & Technology Themes & $\begin{array}{c}\text { Identity } \\
\text { Independence } \\
\text { Quality of Life } \\
\text { Ethics/rights } \\
\text { Social participation } \\
\text { Communication }\end{array}$ \\
\hline User Needs and New Technology Requirements & 7 & Technology Requirements & $\begin{array}{c}\text { Older people-home } \\
\text { Older people-residential home } \\
\text { Family } \\
\text { Nurse staff } \\
\text { Care staff } \\
\text { Nurse Management } \\
\text { Preadmissions } \\
\text { Admissions }\end{array}$ \\
\hline Expected benefits of new technology & 8 & Expected benefits of technology & $\begin{array}{l}\text { Resident } \\
\text { Nurse } \\
\text { Org } \\
\text { Family }\end{array}$ \\
\hline Expected problems/barriers & 9 & Expected technology problems & $\begin{array}{c}\text { Reduction in Human contact } \\
\text { Tech ability } \\
\text { Cost } \\
\text { Workload }\end{array}$ \\
\hline Implementation & 10 & Issues for Implementation & $\begin{array}{c}\text { Home } \\
\text { Residential Home } \\
\text { AL Community } \\
\text { Palliative }\end{array}$ \\
\hline
\end{tabular}


Appendix G. Examples of Version 1 Prototypes

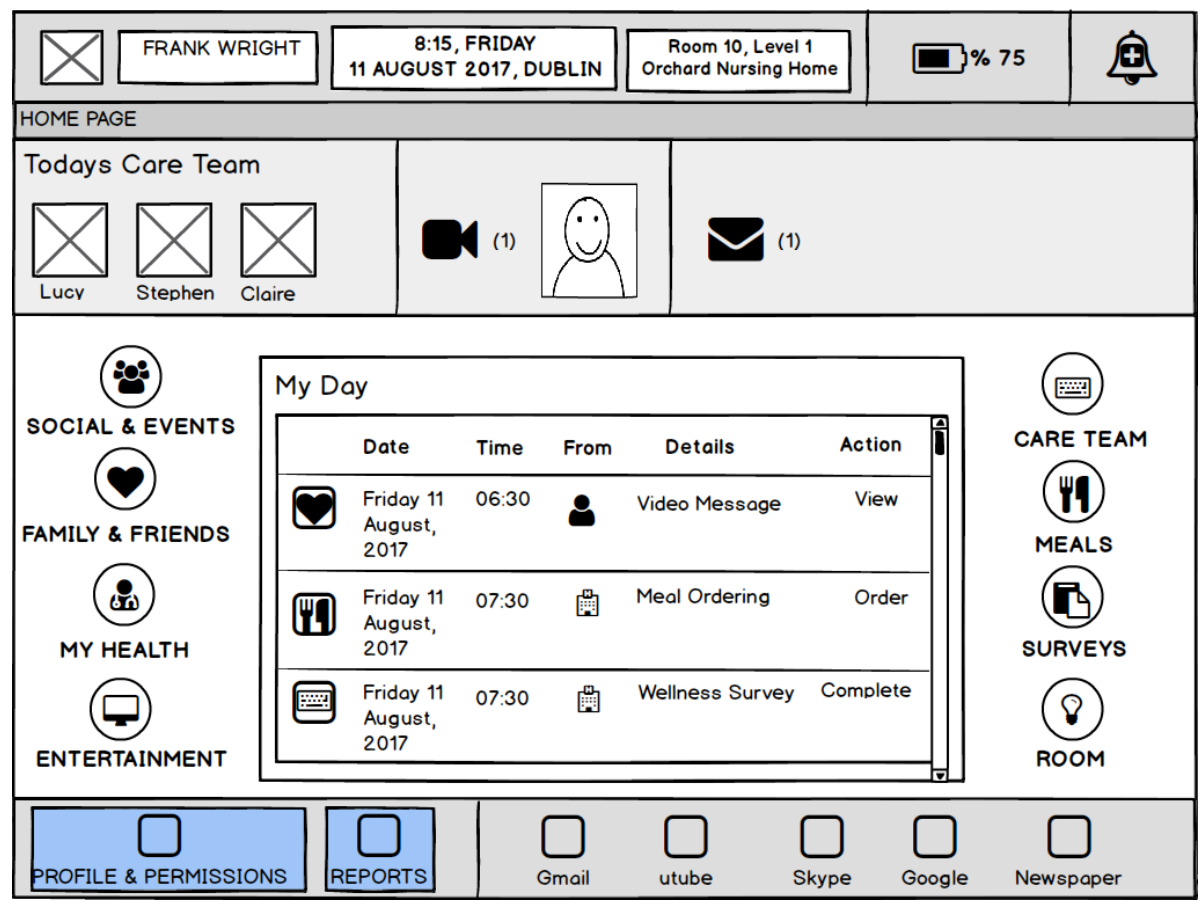

Figure A1. Resident Application: Dashboard (Power User).

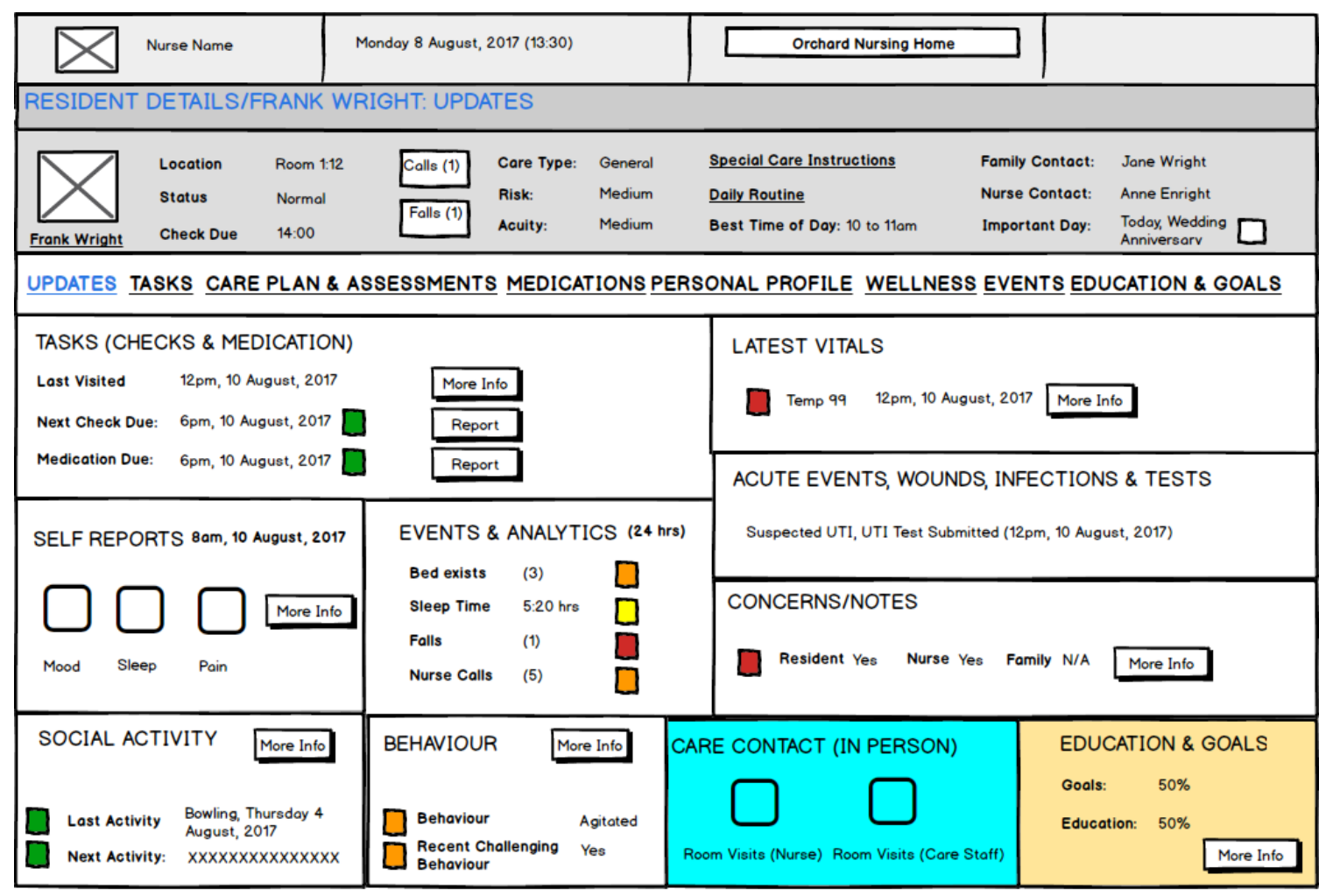

Figure A2. Nurse Application: Resident Status Screen. 


\section{Appendix $\mathrm{H}$.}

Table A7. Resident Menu and Associated Functions.

\begin{tabular}{ccl}
\hline$\#$ & Resident Menu Item & \multicolumn{1}{c}{ Description of Menu Functions } \\
\hline 1 & Family and Friends & Add contact, email or message contact, send photo \\
\hline 2 & Social and Events & $\begin{array}{l}\text { View clubs information, view club events, view residential } \\
\text { home events, view community events, register for event }\end{array}$ \\
\hline 3 & Care Team & Contact care team \\
\hline 4 & Surveys & Complete surveys—-sleep, mood, pain, care feedback \\
\hline 5 & Entertainment & $\begin{array}{l}\text { View TV, Listen to Music, Add media, View recommendations } \\
\text { for media based on mood/sleep }\end{array}$ \\
\hline 6 & My Health & View health information, view assessments, view care plan \\
\hline 7 & Meals & Order food for self or guests \\
\hline 9 & Concierge & Order taxi, request room cleaning, request maintenance \\
\hline
\end{tabular}

\section{Appendix I. Nurse Rounding: Summary Screen}

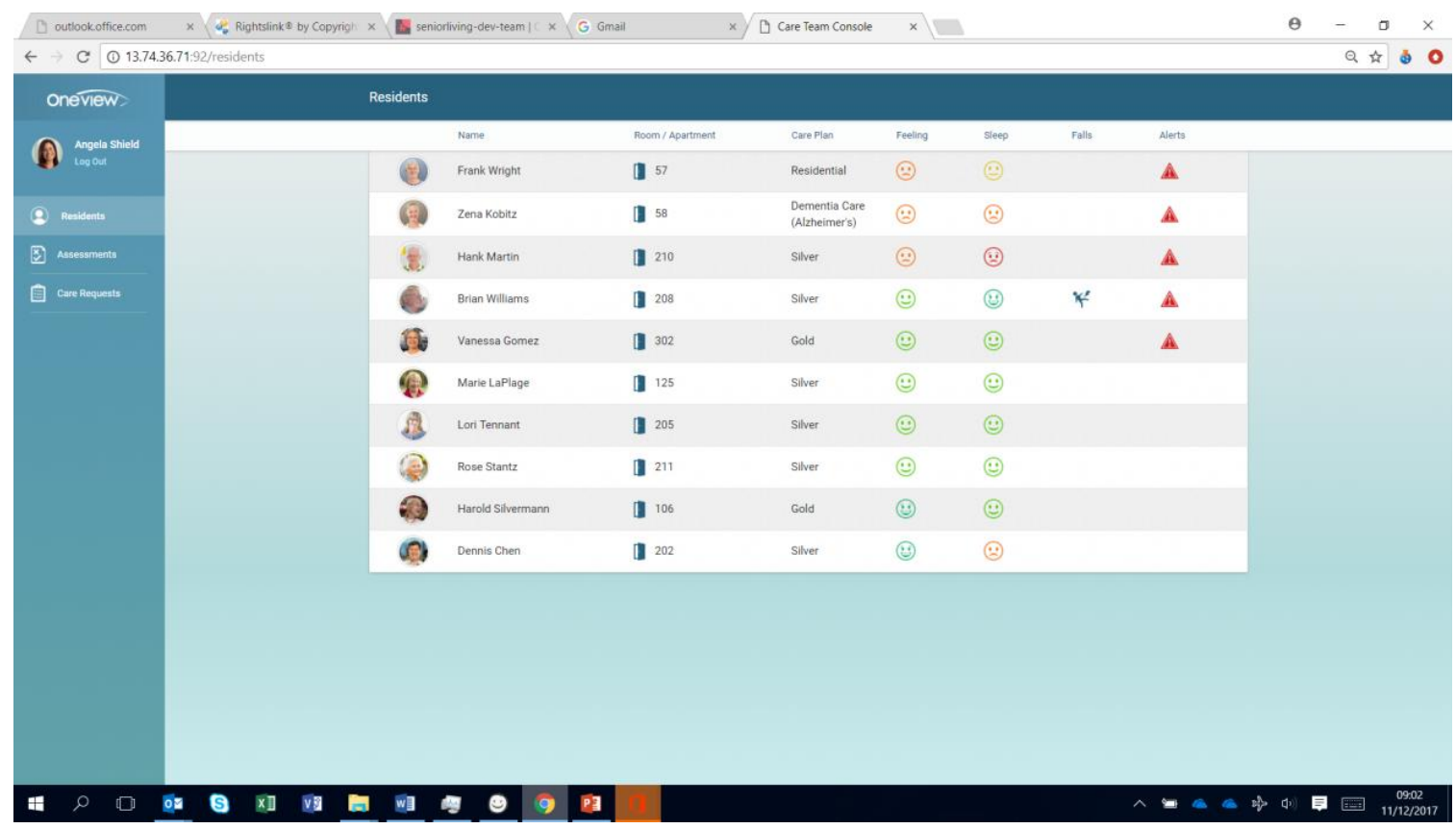

Figure A3. Nurse Application: Resident Summary Screen. 


\section{Appendix J. Nurse Rounding: Resident Details Screen}

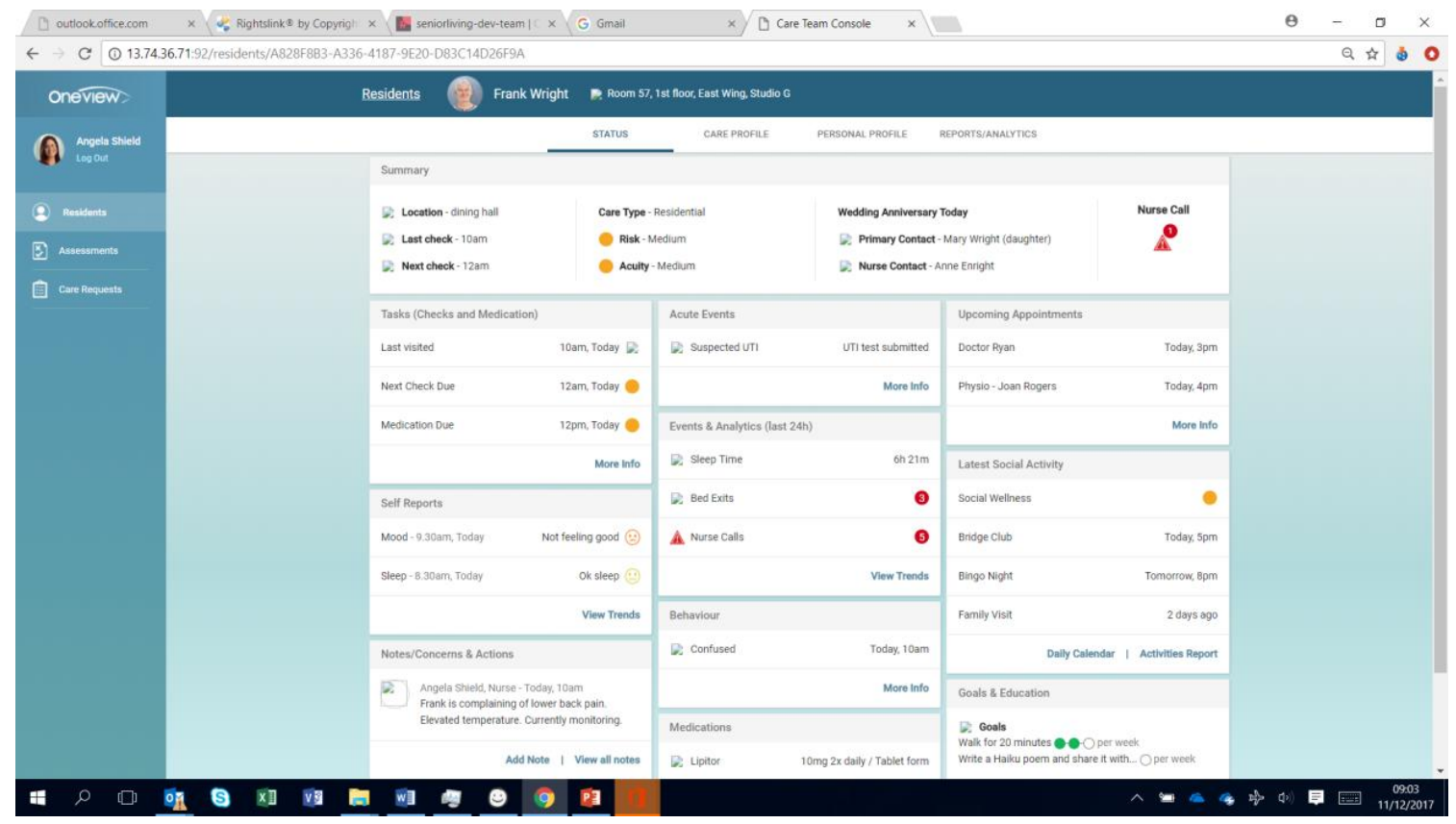

Figure A4. Nurse Application: Resident Details Screen.

\section{References}

1. Engel, G. The need for a new medical model: A challenge for biomedical science. Science 1977, 196, $126-129$. [CrossRef]

2. Havelka, M.; Lucanin, J.D.; Lucanin, D. Biopsychosocial model-The integrated approach to health and disease. Coll. Antropol. 2009, 33, 303-310. [PubMed]

3. Porter, R. The Greatest Benefit to Mankind. A Medical History of Humanity from Antiquity to the Present; HarperCollins: London, UK, 1997.

4. Rowe, J.W.; Kahn, R.L. Successful Aging; Pantheon Books: New York, NY, USA, 1998.

5. Silverstein, M.; Parker, M.G. Leisure activities and quality of life among the oldest old in Sweden. Res. Aging 2002, 24, 528-547. [CrossRef]

6. Leonard, W.M. Successful aging: An elaboration of social and psychological factors. Int. J. Aging Hum. Dev. 1982, 14, 223-232. [CrossRef]

7. Starfield, B. Is Patient-Centered Care the Same As Person-Focused Care? Perm. J. 2011, 15, 63-69. [CrossRef] [PubMed]

8. Kitwood, T. Dementia Reconsidered: The Person Comes First; Open University Press: Buckingham, UK, 1997.

9. Nolan, M. Relationship-centred care: Towards a new model of rehabilitation. Int. J. Ther. Rehabil. 2002, 9, 472-477. [CrossRef]

10. Soklaridis, S.; Ravitz, P.; Adler, G.; Nevo, A.; Lieff, S. Relationship-centered care in health: A 20-year scoping review. Patient Exp. J. 2016, 3, 130-145.

11. Beach, M.C.; Inui, T. Relationship-Cantered Care Research Network. Relationship-centered care: A constructive reframing. J. Gen. Intern. Med. 2006, 21 (Suppl. S1), S3-S8. [CrossRef] [PubMed]

12. Rodgers, V.; Neville, S. Personal autonomy for older people living in residential care: An overview. Nurs. Prax. N. Z. 2007, 23, 29-36. [PubMed]

13. Barnes, M.; Blom, A.; Cox, K. The Social Exclusion of Older People: Evidence from the First Wave of the English Longitudinal Study of Ageing (ELSA): Final Report; Office for the Deputy of Prime Minister: London, UK, 2006.

14. Perkins, M.M.; Ball, M.M.; Whittington, F.J.; Hollingsworth, C. Relational Autonomy in Assisted Living: A Focus on Diverse Care Settings for Older Adults. J. Aging Stud. 2012, 26, 214-225. [CrossRef] [PubMed] 
15. Hillcoat-Nallétamby, S. The meaning of "independence" for older people in different residential settings. J. Gerontol. Ser. B Psychol. Sci. Soc. Sci. 2014, 69, 419-430. [CrossRef] [PubMed]

16. Ferrand, G.; Martinent, N.; Durmaz, N. Psychological need satisfaction and well-being in adults aged 80 years and older living in residential homes: Using a self-determination theory perspective. J. Aging Stud. 2014, 30, 104-111. [PubMed]

17. O'Connor, B.P.; Vallerand, R.J. Motivation, self-determination, and person environment fit as predictors of psychological adjustment among nursing home residents. Psychol. Aging 1994, 9, 189-194.

18. Niemeijer, A.R.; Frederiks, B.J.M.; Riphagen, I.I.; Legemaate, J.; Eefsting, J.A.; Hertogh, C.M.P.M. Ethical and practical concerns of surveillance technologies in residential care for people with dementia or intellectual disabilities: An overview of the literature. Int. Psychogeriatr. 2010, 22, 1129-1142. [CrossRef] [PubMed]

19. Ross, P. Electronic Surveillance in Health and Social Care Settings: A Brief Review; SCIE; Care Quality Commission: Glasgow, UK, 2014.

20. Wetherall, S. Creating Ambient Care Environments. Oneview Healthcare Internal Report. Unpublished work, 2016.

21. Valtorta, N.; Hanratty, B. Loneliness, isolation and the health of older adults: Do we need a new research agenda? J. R. Soc. Med. 2012, 105, 518-522. [CrossRef] [PubMed]

22. Holt-Lunstad, J.; Smith, T.B.; Layton, J.B. Social Relationships and Mortality Risk: A Meta-analytic Review. PLoS Med. 2010, 7, E1000316. [CrossRef] [PubMed]

23. Khosravi, P.; Rezvani, A.; Wiewiora, A. The impact of technology on older adults' social isolation. Comput. Hum. Behav. 2016, 63, 594-603. [CrossRef]

24. Campaign to End Loneliness. Technology: Will It Ever Be a Fix for Loneliness? Available online: https: / /www. campaigntoendloneliness.org/blog/technology-loneliness-fix (accessed on 13 November 2017).

25. National Clinical Incidents and Claims Report: A Five Year Review. Available online: http://stateclaims.ie/wpcontent/uploads /2017/05/State-Claims-Agency-National-Clinical-Incidents-Claims-and-Costs-Report.pdf (accessed on 16 January 2018).

26. Gawande, A. Being Mortal: Illness, Medicine and What Matters in the End; Profile Books: London, UK, 2015.

27. European Charter of Rights and Responsibilities of Older People in Need of Long Term Care and Assistance. Available online: http:/ / www.age-platform.eu/images/stories/22204_AGE_charte_europeenne_EN_v4. pdf (accessed on 16 January 2018).

28. Alzheimer's Society. Human Rights and Older People in Ireland, Policy Paper. Available online: https://www. alzheimer.ie/Alzheimer/media/SiteMedia/ImageSlider/Fixed/ASI-HROP-A4-Online-Report.pdf (accessed on 26 January 2018).

29. The European Convention for the Protection of Human Rights and Fundamental Freedoms as Amended by Protocols No. 15. Available online: https:/ / rm.coe.int/1680063765 (accessed on 16 January 2018).

30. The Assisted Decision-Making (Capacity) Act 2015. Relate 2015. Available online: http://www. citizensinformationboard.ie/downloads/relate/relate_2016_04.pdf (accessed on 16 January 2018).

31. Cahill, J.; McLoughlin, S.; Wetherall. Harnessing the Power of Technology to Improve Lives; Ebook; IOS Press: Berlin, Germany, 2017; pp. 64-71, ISBN1 978-1-61499-797-9, ISBN2 978-1-61499-798-6.

32. Cahill, J.; McLoughlin, S.; Wetherall, S.; Stolberg, M.; O'Connor, M. Addressing issues of need, adaptability, user acceptability and ethics in the participatory design of new technology enabling wellness, independence and dignity for seniors living in residential homes. In Proceedings of the Third International Conference on Human Aspects of IT for the Aged Population (Part 11) (ITAP 2017), Held as Part of HCI International 2017, Vancouver, BC, Canada, 9-14 July 2017; Springer: Berlin/Heidelberg, Germany, 2017.

33. ISO 6385. 2016. Available online: https://www.iso.org/standard/63785.html (accessed on 16 January 2018).

34. Cousins, J.B.; Whitmore, E.; Shulha, L. Arguments for a Common Set of Principles for Collaborative Inquiry in Evaluation. Am. J. Eval. 2013, 34, 7-22. [CrossRef]

35. Wenger, E. Communities of Practice: Learning, Meaning, and Identity; Cambridge University Press: Cambridge, UK, 1998.

36. Van Maanen, J. Tales of the Field: On Writing Ethnography; University of Chicago Press: Chicago, IL, USA, 1988.

37. Hammersley, M.; Atkinson, P. Ethnography: Principles in Practice, 3rd ed.; Routledge: London, UK, 2007.

38. Soegaard, M.; Rikke Friis, D. Ethnography. In Encyclopedia of Human Computer Interaction, 2nd ed.; Randall, D., Rouncefield, M., Eds.; 2006; Chapter 31; Available online: https:/ / www.interaction-design.org/literature/ book/the-encyclopedia-of-human-computer-interaction-2nd-ed (accessed on 16 January 2018). 
39. Lindseth, A.; Norberg, A. A phenomenological hermeneutical method for researching lived experience. Scand. J. Caring Sci. 2004, 18, 145-153. [CrossRef] [PubMed]

40. Pruitt, J.; Grudin, J. Personas: Practice and Theory. In Proceedings of the 2003 Conference on Designing for User Experiences (DUX'03), San Francisco, CA, USA, 6-7 June 2003; ACM: New York, NY, USA, 2003; pp. 1-15. [CrossRef]

41. Carroll, J.M. Scenario-Based Design: Envisioning Work and Technology in System Development; John Wiley and Sons: New York, NY, USA, 1995.

42. Bødker, S.; Burr, J. The Design Collaboratorium. A Place for Usability Design. ACM Trans. Comput. Hum. Interact. 2002, 9, 152-169. [CrossRef]

43. WMA General Assembly. Declaration of Helsinki. In Proceedings of the 64th WMA General Assembly, Fortaleza, Brazil, 11-14 October 2013.

44. Rosson, M.B.; Carroll, J. Usability Engineering: Scenario-Based Development of Human-Computer Interaction (Interactive Technologies), 1st ed.; Morgan Kaufmann Publishers: San Francisco, CA, USA, 2002.

45. Goodwin, K. Storytelling by Design. 2011. Available online: https://www.slideshare.net/KimGoodwin/ storytelling-by-design-scenarios-talk-at-confab-2011 (accessed on 16 January 2018).

46. Green, J.; Thorogood, N. Qualitative Methods for Health Research; Sage: Los Angeles, CA, USA, 2013.

47. Cahill, J.; Bokser, S.; McLoughlin, S. Addressing independence and lived experience: New technologies to support wellness, independent living, social participation and community engagement. Presented at the Ageing and Society Conference, Berkeley, CA, USA, 3-4 November 2017.

(C) 2018 by the authors. Licensee MDPI, Basel, Switzerland. This article is an open access article distributed under the terms and conditions of the Creative Commons Attribution (CC BY) license (http:/ / creativecommons.org/licenses/by/4.0/). 